$11-2013$

\title{
Preferences, Structure, and Influence: The Engineering of Consent
}

Witold J. Henisz

University of Pennsylvania

Follow this and additional works at: https://repository.upenn.edu/mgmt_papers

Part of the Business Administration, Management, and Operations Commons, Business and Corporate Communications Commons, Business Intelligence Commons, Cognition and Perception Commons, Cognitive Psychology Commons, International Business Commons, Interpersonal and Small Group Communication Commons, Management Information Systems Commons, Management Sciences and Quantitative Methods Commons, Policy Design, Analysis, and Evaluation Commons, Social Psychology Commons, and the Strategic Management Policy Commons

\section{Recommended Citation}

Henisz, W. J. (2013). Preferences, Structure, and Influence: The Engineering of Consent. Global Strategy Journal, 3 (4), 338-359. http://dx.doi.org/10.1111/j.2042-5805.2013.01064.x

This paper is posted at ScholarlyCommons. https://repository.upenn.edu/mgmt_papers/328

For more information, please contact repository@pobox.upenn.edu. 


\title{
Preferences, Structure, and Influence: The Engineering of Consent
}

\author{
Abstract \\ I present a decision process framework that informs the design and implementation of stakeholder \\ influence strategy. This process combines insights from agent-based dynamic utility and dynamic \\ network processes. Stakeholders strategically seek an outcome as close as possible to their preferred \\ point but also wish to be on the winning side and not to pursue positions divergent from stakeholders \\ with whom they have strong affective ties. Simulation analysis highlights important effects from \\ embedding stakeholders within such an interdependent policymaking network. The resulting decision \\ process framework can be used by firms to assess the likely dynamics within such a stakeholder network \\ as well as to compare alternative treatments to that network for their efficacy in securing a favorable \\ policy outcome, collective decision, or shift in group opinion.

\section{Keywords} \\ stakeholder, agent-based model, social network, coalition politics, decision process

\section{Disciplines} \\ Business Administration, Management, and Operations | Business and Corporate Communications | \\ Business Intelligence | Cognition and Perception | Cognitive Psychology | International Business | \\ Interpersonal and Small Group Communication | Management Information Systems | Management \\ Sciences and Quantitative Methods | Policy Design, Analysis, and Evaluation | Social Psychology | \\ Strategic Management Policy
}




\title{
Preferences, Structure and Influence: The Engineering of Consent
}

\author{
Witold J. Henisz \\ UPS Visiting Associate Professor of Civil and Environment Engineering \\ Jerry Yang and Akiko Yamikaze Energy and Environment Building \\ 473 Via Ortega, Room 305 \\ Stanford University \\ Stanford, CA 94305-4020 \\ Tel: (650) 721-1135 \\ Fax: (650) 725-8662 \\ Email:wjhenisz@stanford.edu \\ and \\ Associate Professor of Management (on leave) \\ The Wharton School \\ 3107 Steinberg Hall-Dietrich Hall \\ 3620 Locust Walk \\ University of Pennsylvania \\ Philadelphia, PA 19104-6370 \\ Tel: (215) 898-0788 \\ Fax: (215) 898-0401 \\ Email: henisz@wharton.upenn.edu
}

Friday, April 24, 2009

\section{***HIGHLY PRELIMINARY AND INCOMPLETE DRAFT*** \\ ***PLEASE DO NOT CITE OR CIRCULATE***}

Special thanks to Alan Kelly for his feedback on and input into the formalization of his decisionmaking framework (Kelly, 2006), Marc Ramsey for long hours and great patience in developing, programming and implementing the simulation analysis, the financial and intellectual support from the Collaboratory for Research on Global Projects at Stanford University and the students of CEE 341 "Politics and Infrastructure Investment" at Stanford University. 


\title{
Preferences, Structure and Influence: \\ The Engineering of Consent
}

\begin{abstract}
I present a decision process framework that informs the design and implementation of influence strategy. This process combines insights from agent-based dynamic utility and agent-based dynamic network processes as well as an existing decision framework for stakeholder influence strategies that lacks these micro-foundations. I subject the resulting decision process to simulation analysis that reveals the environmental and strategic determinants of the efficacy of various influence strategies. Preliminary simulation analysis highlights import effects from embedding actors within a policymaking network as compared to treating them as wholly autonomous agents. Subsequent analysis will allow for endogenous variation not only in preferences but also issue salience, beliefs, tie strength and tie affect.
\end{abstract}


Leaders may be the spokesmen for many different points of view. They may direct the activities of major organized groups such as industry, labor, or units of government. They may compete with one another in battles for public good will; or they may, representing divisions within the larger units, compete amongst themselves. Such leaders, with the aid of technicians in the field who have specialized in utilizing the channels of communication, have been able to accomplish purposefully and scientifically what we have termed "the engineering of consent."

This phrase quite simply means the use of an engineering approach - that is action that is based only on thorough knowledge of the situation and on the application of scientific principles and tried practices to the task of getting people to support ideas and programs. Any person or organization depends ultimately on public approval, and is therefore faced with the problem of engineering the public's consent to a program or goal...

When the public is convinced of the soundness of an idea, it will proceed to action. People translate an idea into action suggested by the idea itself, whether it is ideological, political, or social. They may adopt a philosophy that stresses racial and religious tolerance; they may vote a New Deal into office; or they may organize a consumers' buying strike. But such results do not just happen. In a democracy, they can be accomplished principally by the engineering of consent. (Bernays, 1947: pp. 114, 120)

\section{Introduction}

Influence strategies involve strategic behavior by actors embedded in a network of economic, political and social relationships who seek to alter the preferences, beliefs or network structure in which they are embedded to secure a favorable policy outcome, collective decision or shift in group opinion. Such strategies are ubiquitous elements of the interaction of individuals, groups, organizations, coalitions, and societies. They are used by individuals seeking to influence team decision-making and organizational politics as well as by individuals and organizations in lobbying, marketing, sales, political campaigns and corporate, national or multilateral projections of soft power. Elements of such strategies have been subject to analysis but the process as a whole remains more art than science. In this paper, I combine elements of decision processes from political economy and social network analysis with a formalization of a decision framework for stakeholder influence to offer an interdisciplinary decision process framework that informs the design and implementation of influence strategy. I propose to analyze the environmental and strategic determinants of the efficacy of various influence strategies using agent-based simulation.

The foundation of the decision process framework is the dynamic expected utility decision process developed by Bruce Bueno de Mesquita (De Mesquita, 1980, 1981, 1983, 1984, 1985, 1992, De 
Mesquita \& Lalman, 1986, 1987, 1988) which allows for strategic interaction by utility maximizing autonomous actors over time to minimize their loss functions in a unidimensional policy space. Actors make choices recognizing that their peers are also behaving strategically albeit under constraints of bounded rationality (i.e., behavior that is intendedly rational but only limitedly so), that utility is derived when the policy outcome is proximate to an actors' ideal point and when an actor is on the winning team, and that beliefs regarding certain actor attributes may diverge from reality. The key attributes are each actor's ideal point in the policy space, actor power, issue salience and beliefs regarding the issue salience of other actors which together determine an actor's choice of whether to seek to influence others, accede in whole or in part to the influence of others by altering their policy position or stand firm in anticipation of an eventual "vote" or "competition" based upon a forward looking analysis of the expected utility of such a "play".

To this foundation I add insight from social network analysis (Wasserman \& Faust, 1997) to better represent actors as embedded in a network structure than both enables and constrains their behavior. Specifically, I allow the parameters of actor power, utility, issue salience and the beliefs regarding peers' issue salience to vary according to the position of an actor in the policy network. In this manner, I capture the influence of peers and position on a focal actor's behavior privileging those peers whose position in the overall policy network affords them prominence. As a result, both the nature of the ties between any one actor and his or her peers and the overall structure of the network influence the preferences and beliefs of the focal actor.

Finally, I enrich the strategic behavior of each agent by drawing upon a decision framework developed for stakeholder influence developed by Alan Kelly (2006). Kelly (2006) proposes "the first classification system of moves and countermoves that people and organizations employ in business, politics and popular culture...to influence the opinions, perceptions, behaviors and decisions of our always unique and ever-competitive marketplace." In his decision framework, actors can choose from 
twenty-five 1 "plays" that involve some combination of the selective provision of information, adaptations in policy proposals that reference alternative frames or otherwise seek to draw in peer actors into a coalition and efforts to alter the structure (i.e., the strength of ties or level of affect between two actors) of the policy network. Kelly's (2006) system is the first attempt to isolate the distinctive influence strategems that playmakers employ in their craft. In consultation with Kelly, I codified his "plays" as having specific probabilities of successfully transforming various parameters in the decision process. Most plays also have probabilities of failing and many can backfire having unintended negative consequences on certain parameters.

I propose to subject this augmented decision process of preferences, structure and influence to analysis using agent-based simulation which will allow me to identify changes in the distribution of strategy sequences by actors as a function of changes in the structure of the game including the distance between an actor's preferred policy and that of the median voter, the effective power of an actor (i.e., their power multiplies by their issue salience), the nature of their ties to other actors in the policy network and the concurrent and prior moves by other actors. The results of this exercise offer the potential both for a positive analysis of the evaluation of the efficacy of influence strategies as well as a prescriptive system for their design and even a predictive system for anticipating the best moves of players. After acknowledging the limitations of the approach, I close by highlighting its potential contributions including mechanisms to qualitatively and quantitatively test the decision process as well as some fruitful directions to extend the theory.

\section{Relationship to Existing Theory and Tools}

At the core of the decision process is the dynamic expected utility process of Bruce Bueno de Mesquita which

is concerned with explaining how policy positions of competing players evolve over time and shape policy outcomes. Therefore, it leads to predictions about policy outcomes and identifies

\footnotetext{
${ }^{1}$ Three of the twenty-eight plays considered in this paper are treated as surrogate plays by Kelly (2006).
} 
strategic opportunities for altering them. As such it can be used to explain and predict political decisions at any level of analysis, including, of course, foreign policy and international relations. It can also be used by policy makers to anticipate outcomes and to reshape them to be more in line with their own interests. (De Mesquita, 1992: p. 51)

This decision process developed over two decades in dozens of academic publications offers a rigorous game theoretic assessment of the political strategies of utility maximizing actors defined by a level of power, an ideal point, a degree of issue salience and a set of beliefs regarding the issue salience of their peers. The decision process was originally developed to forecast interstate ${ }^{2}$ or intrastate $^{3}$ negotiations that could lead to conflict but over time expanded in its application to consider a broader array of policy outcomes including privatization and regulation. ${ }^{4}$ It was originally commercialized by Decision Insights Incorporated ${ }^{5}$ and has been extensively validated and used by the United States Government (Feder, 2002) as well as The McKinsey Group (Allas \& Georgiades, 2001).

Like other agent-based models used in political economy (Acemoglu \& Robinson, 2006, Grossman \& Helpman, 2001, Persson \& Tabellini, 2002), the dynamic expected utility decision process assumes rational behavior by a set of utility maximizing actors with either perfect information about the nature of their interaction or imperfect information of a type that can be formally specified or parameterized. It makes two further key assumptions for the sake of analytic tractability: "(1) that issues are unidimensional, so that preferences can be represented on a line segment; and (2) that preferences (and associated utilities) for potential outcomes diminish steadily the farther in Euclidean distance a possible settlement is from one's preferred outcome." (De Mesquita, 1992: p. 51). Actors then make decisions regarding efforts to influence others into shifting their position and responding to such

\footnotetext{
${ }^{2}$ Examples include Kosovo, China and Hong Kong, the South China Sea, Arab-Israeli disputes, French participation in the Strategic Defense Initiative, Philippine policy towards U.S. military bases, Pakistan's position on Soviet occupation of Afghanistan, relations between Mozambique and the United States, Chinese reaction to Taiwanese accession to Asian Development Bank and South Yemeni support for North Yemeni insurgents.

${ }^{3}$ Examples include the stability of the Soviet Union, Russia, China, Saudi Arabia, India, Iraq, Korea, Brazil, Italy, Yugoslavia and Northern Ireland.

${ }^{4}$ Examples include EU civil aviation as well as national policies in Poland, Czechoslovakia and Italy; legislative reform of health care in the United States; corruption reform in Mexico; liberalization of trade in the United States and Japan or investment in Sri Lanka; earmarking and other funding authorizations within the US, EU and China; standards regarding radioactivity in food and auto emissions among EU nations; regulatory rulings on rates of return in the US and EU; government approvals of mergers in the US and EU; and multiple policy decisions associated with the advent of the Euro including the French referendum on acceding to the Maastricht Treaty

${ }^{5}$ See Hhttp://www.diiusa.com/experience.htmlH
} 
entreaties from others with the aim of maximizing their individual utility assuming other actors are behaving similarly. The game continues until policy converges (i.e., the expected change in policy from one round to the next declines below some threshold).

Following a growing body of literature in social science (Freeman, White, \& Romney, 1989, Knoke \& Yang, 2008, Wasserman \& Faust, 1997), I seek to acknowledge and model the importance of the network ties between various actors in this policymaking space. I wish to augment the dynamic expected utility decision process's assumption of independently determined actor characteristics and allow for structural relations between actors to rival or even exceed the importance of actor attributes in shaping beliefs and influencing actions (Knoke \& Yang, 2008). Social network analysis has expanded far beyond its origins in the study of classroom interactions and work groups expanding to improve our understanding of such diverse phenomena as kinship, urbanization, "social mobility, class structure, perceptions of class, corporate power, international trade exchanges, contacts with deviant groups, welfare support, science citation, migration patterns and reactions to disasters" (Scott, 1988: p. 116). The focus of recent research has further expanded to include social media, blogging, epidemiology, national security, innovation and alliances. Like the dynamic expected utility decision process of Bueno de Mesquita, social network analysis is also used by government (Borgatti, 2006) and business (Cross, Borgatti, \& Parker, 2002) to improve strategic decisionmaking ${ }^{6}$ although applications to political influence strategies remain descriptive (Barley, 2007, Knoke, 1990, 1990, 1996, Laumann \& Knoke, 1987). I seek to build tractable analytics onto these descriptive foundations by incorporating wellestablished positional metrics of the similarity between actors in structural position (i.e., structural equivalence) (Wasserman \& Faust, 1997: Ch. 9) and of power (i.e., centrality) (Bonacich, 1987) into dynamic expected utility decision processes much as has occurred in other domains where network analysis has long been applied (see, for example in the context of innovation, Owen-Smith \& Powell (2004) and Powell et. al. (2005).

\footnotetext{
${ }^{6}$ See also Hhttp://www.orgnet.comH
} 
As opposed to the focal question in most studies using social network analysis, I am interested not in the best manner to explain, promote or retard diffusion of a practice but how an actor can best alter the collective preferences regarding a practice within a policy network with the aim of altering the policy outcome of that network. Each actor is both influenced by their peers in the policy network but also seeks to influence them so as to maximize their utility. In this regard, my decision process shares many features with the dynamic network processess of Tom Snijders and his collaborators (Burk, Steglich, \& Snijders, 2007, Mercken, Snijders, Candel, Steglich, \& De Vries, 2005, Snijders, Steglich, \& van de Bunt, 2008, Steglich, Snijders, \& Pearson, 2007). As in these systems, I explicitly allow for various forms of endogenous network formation and restructuring. Dynamic network processes that either allow for actors with similar behavior to form ties or for actors with preexisting ties to adopt similar behavior (or both) have been powerful tools for the analysis of outcomes such as the transmission of sexually transmitted diseases or greater interdisciplinary collaboration among academics. By better identifying the nature of the causal relationship between network position and behavior such analysis allows for the identification of policy innovations that can "nudge" or "tip" equilibria onto more desirable and self-enforcing paths. My decision process shares with these efforts a balance between agent-based and network-based determinants of actor behavior. My depiction of the agent-based decisionmaking process is, however, substantially richer drawing upon the dynamic expected utility decision processes described above.

Formally, I define an actor's preferences as a linear combination of the autonomously determined utility formulation based upon the distance from an actor's ideal point and the autonomously determined utility of other actor's in the network. I construct measures that allow for other actor's to have greater weight on the focal actor if those peers have higher status (i.e., possess greater ties to alters with greater ties) $^{7}$ or share a similar structural position in the network (i.e., are structurally equivalent).

I also allow network structure to alter each actor's power. Here, in contrast to the communication or diffusion processes of social networks, ties to (powerful) actors that have fewer outside options (i.e., possess fewer ties) convey greater power. This insight regarding the importance of brokerage positions

\footnotetext{
${ }^{7}$ Formally, as described in more detail below, I adopt the Bonacich (1987) measure of centrality with $\beta=0.5$.
} 
providing privileged connections across structural holes (Burt, 1992, Burt, 1997, Burt, 1987) has been validated in studies of entrepreneurship, innovation, organizational learning and performance (Burt, 2004). Total power is thus a weighted function of autonomously determined power and the power derived by connections to (powerful) peer actors with few other ties. ${ }^{8}$

Finally, I seek to augment the strategic moves available to individual actors beyond both the choice set of proceeses developed in political economy and sociology. For a richer constellation of influence strategies, I draw upon the recent publication of Alan Kelly (2006) entitled The Elements of Influence. Based upon observation, his experience in advising high tech companies prior to and through during the dotcom era including Oracle in their long-term battle with Microsoft over the prospects for network computing and a multi-disciplinary review of relevant literatures in political science, communications, psychology, anthropology, military history, marketing, competitive strategy, law, philosophy, artificial intelligence, negotiations, propaganda and beyond, Kelly developed what he posits is a comprehensive typology for the discipline of "playmaking"

"Playmaking is the new and necessary skill for anyone who advocates for an idea, touches an organization's brand, influences its reputation, or is in any way involved in the development of policy, message, communication to stakeholders, or the management of the media." (Kelly, 2006: 14)

While Kelly offers a rich and thorough description of each play, the class and sub-class to which it belongs, well-known examples of each play drawn from multiple domains, "upsides", “downsides", "related terms", rationales for running the play as well as tips for decoding and countering it when it is run on you, the presentation is largely anecdotal and descriptive. While each play is intuitive in its description and the overall framework has been tested both in the graduate classroom and in the field via numerous client engagements with Fortune 100 companies, the ability of the reader or the academic to systematically match a given play to a set of environmental circumstances is limited, at least for those lacking decades of experience on which to build a gut instinct, by the lack of a tractable micro-level specification of the determinants of playmaker's behavior. By parameterizing Kelly's plays within my

\footnotetext{
${ }^{8}$ Formally, as described in more detail below, I adopt the Bonacich (1987) measure of centrality with $\beta=-0.5$.
} 
agent-based dynamic network utility decision process, I extend the strategic plays available to policymakers in dynamic expected utility decision processes and nodal actors in dynamic network processes while also providing more methodological rigor for the assessment of appropriate plays and counterplays. I next turn to the depiction of this dynamic expected utility network decision process.

\section{The Dynamic Expected Utility Network Decision Process}

Each of the $\mathrm{n}$ actors in the game begins positioned at their ideal points. In each round, each player broadcasts their current position (i.e., makes a proposal) to every other player. Based on these received proposals, each player i assesses, the credibility of the received proposals (i.e., would the received proposal be expected to beat the status quo policy in a vote); their expected utility from challenging the proposal (i.e., (the expected probability that the received proposal would defeat i's proposal * i's utility if the received proposal wins $)+(1-$ the expected probability that the received proposal would defeat i's proposal * i's if i's proposal wins); and their expected utility from not challenging the proposal (i.e., i's expected utility at the status qup - i's expected utility if all other players play their best strategy). Actor i chooses the credible proposal whose net expected utility for $\mathrm{i}<0<$ net expected utility for $\mathrm{j}$ that minimizes their loss in utility. Calculating the expected utilities and the expected probability of one proposal beating another requires the computation of the following antecedent calculations.

Each actor $i$ is characterized by

(1) an ideal point in a unidimensional continuous policy space $[0,1]$

$$
0 \leq i p_{i} \leq 1
$$

(2) an autonomously determined amount of power

$$
a w_{i} \geq 0
$$

normalized such that the sum of all actors power $=1$

$$
\overline{a w_{l}}=\frac{a w_{i}}{\left(\sum_{j=1}^{n} a w_{j}\right)}
$$


(3) an autonomously determined strength of preferences or issue salience (i.e., the degree to which they are willing to deploy their power - time and financial resources - on this issue as opposed to others on which they may have preferences)

$$
0 \leq a s_{i} \leq 1
$$

(4) a set of beliefs regarding the strength of preferences or issue salience of other actors

$$
0 \leq b_{i j} \leq 1^{9}
$$

(5) a set of ties to other actors which vary in strength and in affect

$$
\begin{aligned}
& 0 \leq t s_{i j} \leq 1 \\
& -1 \leq t a_{i j} \leq 1
\end{aligned}
$$

Based upon these parameters, it is possible to calculate each actor's

(6) Utility at each point in the policy space which is a weighted function of the focal actor's autonomously determined utility, the autonomously determined utility of actors with whom the focal actor is directly tied and the autonomously determined utility of actors with whom the focal actor is structurally equivalent. This utility is not linear in distance but rather incorporates a risk parameter that allows actors whose preferences are further from that of the mean voter to be more tolerant of risk whereas those closest to the mean voter are willing to tradeoff a greater deviation from their ideal point for the security provided by being on the winning side.

$$
\begin{aligned}
& u_{i}(m)=(1-\delta-\theta) a u_{i}(m)+\delta t u_{i}(m)+\theta \operatorname{seu}_{i}(m) \\
& a u(m)=\left(1-\left|i p_{i}-m\right|^{r_{i}(m)}\right)
\end{aligned}
$$

\footnotetext{
${ }^{9}$ Beliefs can be chosen as a random parameter, set equal to the true strength of preferences or, most realistically, drawn from a distribution whose mean is equal to the true strength of preferences but whose variance is proportional to the multidimensional scaled distance between actor $i$ and actor $j$ and whose kurtosis is inversely proportional to that distance (i.e., distance from an actor increases the likelihood of error whereas proximity to an actor reduces that likelihood although the potential for large errors increases relative to small errors so as to capture the possibility of proximity bias). I choose this last process for the purposes of the simulation.
} 


$$
r_{i}(m)=\frac{1-\left(\frac{R_{i}(m)}{3}\right)}{1+\left(\frac{R_{i}(m)}{3}\right)}
$$

$R_{i}(m)$

$=\frac{2\left(\sum_{j \neq 1}^{n-1} \bar{w}_{l} b_{i j}\left(1-\left|i p_{i}-m\right|\right)\right)-\left(\sum_{j \neq 1}^{n-1} \bar{w}_{\iota} b_{i j}\left(1-\left|i p_{i}-m_{j: \max }\right|\right)\right)+\left(\sum_{j \neq 1}^{n-1} \bar{w}_{\iota} b_{i j}\left(1-\left|i p_{i}-m_{j: \min }\right|\right)\right)}{\left(\sum_{j \neq 1}^{n-1} \bar{w}_{\iota} b_{i j}\left(1-\left|i p_{i}-m_{j: \max }\right|\right)\right)+\left(\sum_{j \neq 1}^{n-1} \bar{w}_{l} b_{i j}\left(1-\left|i p_{i}-m_{j: m i n}\right|\right)\right)}$

$m_{j: \max }=\operatorname{m:} \max \left\{\sum_{i=1}^{n-1}\left(\overline{w_{l}} b_{i j}\left(1-\left|i p_{i}-m\right|\right)\right)\right\}$

$m_{j: \min }=\operatorname{m}: \min \left\{\sum_{i=1}^{n-1}\left(\overline{w_{l}} b_{i j}\left(1-\left|i p_{i}-m\right|\right)\right)\right\}$

$t u_{i}(m)=\frac{\sum_{\mathrm{j} \neq \mathrm{i}}^{\mathrm{n}-1}\left(\mathrm{cc}_{\mathrm{j}} \mathrm{x}_{\mathrm{ij}}\left(1-\left|\mathrm{ip} \mathrm{p}_{\mathrm{j}}-\mathrm{m}\right|^{\mathrm{r}_{\mathrm{j}}(\mathrm{m})}\right)\right)}{\sum_{j \neq i}^{n-1} x_{i j}}$

$\operatorname{seu}_{i}(m)=\frac{\sum_{\mathrm{j} \neq \mathrm{i}}^{\mathrm{n}-1}\left(\operatorname{se}_{\mathrm{ij}}\left(1-\left|\mathrm{ip} \mathrm{p}_{\mathrm{j}}-\mathrm{m}\right|^{\mathrm{r}_{\mathrm{j}}(\mathrm{m})}\right)\right)}{\sum_{j \neq i}^{n-1} s e_{i j}}$

$x_{i j}=t s_{i j} *\left(t a_{i j}+1\right) / 2$

$S e_{i j}=\frac{\left[1+\frac{\sum_{k \neq i, j}^{n-2}\left(x_{k i}-\overline{x_{\cdot}}\right)\left(x_{k j}-\overline{x_{\cdot j}}\right)+\sum_{k \neq i, j}^{n-2}\left(x_{i k}-\overline{x_{\cdot} \cdot}\right)\left(x_{j k}-\overline{x_{J} \cdot}\right)}{\sqrt{\sum_{k \neq i, j}^{n-1}\left(x_{k i}-\overline{x_{\cdot}}\right)^{2}+\sum_{k \neq i, j}^{n-1}\left(x_{i k}-\overline{x_{l}}\right)^{2}} \sqrt{\sum_{k \neq i . j}^{n-1}\left(x_{k j}-\overline{x_{\cdot}}\right)^{2}+\sum_{k \neq i, j}^{n-2}\left(x_{j k}-\overline{x_{j}}\right)^{2}}}\right]}{2}$

$\overline{x_{\cdot l}}=\frac{\sum_{j \neq i}^{n-1} x_{j i}}{n-1}$

$\overline{x_{l}}=\frac{\sum_{j \neq i}^{n-1} x_{i j}}{n-1}$

$0 \leq \delta \leq 1$, by default $\delta$ set to $=\frac{\sum_{j \neq i}^{n-1} x_{i j}}{2(n-1)}$

$0 \leq \theta \leq 1$, by default $\theta$ set to $=\frac{\sum_{j \neq i}^{n-1} t s_{i j}}{2(n-1)}$

$c c_{i}(\alpha, \beta)=\sum_{j \neq i}^{n-1}\left(\alpha+\beta c c_{j}\right) t s_{i j}$

In matrix notation

$c c(\alpha, \beta)=\alpha\left(I-\beta t s_{i j}\right)^{-1} t s_{i j} 1$

where " 1 " is a column vector of ones, I is the identity matrix, $\beta=0.5$ and $\alpha$ is selected so that 
$\sum_{i=1}^{n}\left(c c_{i}(\alpha, \beta)\right)^{2}=n^{2}$

(7) Issue salience which is a weighted function of the focal actor's autonomously determined issue salience, the autonomously determined issue salience of actors with whom the focal actor is directly tied and the autonomously determined issue salience of actors with whom the focal actor is structurally equivalent

$$
\begin{aligned}
& s_{i}=(1-\delta-\theta) a s_{i}+\delta t_{s s_{i}}+\theta \operatorname{ses}_{i} \\
& t s s_{i}=\frac{\sum_{\mathrm{j} \neq 1}^{\mathrm{n}-1}\left(\mathrm{cc}_{\mathrm{j}} \mathrm{x}_{\mathrm{ij}} A S_{j}\right)}{\sum_{j \neq i}^{n-1} x_{i j}} \\
& \operatorname{ses}_{i}=\frac{\sum_{\mathrm{j} \neq \mathrm{i}}^{\mathrm{n}-1}\left(\mathrm{se}_{\mathrm{ij}} A S_{j}\right)}{\sum_{j \neq i}^{n-1} s e_{i j}}
\end{aligned}
$$

(8) Power which is a weighted function of autonomously determined power and network centrality (i.e., a measure of the connections a focal actor has to other actors weighted by their network centrality)

$w_{i}=(1-\gamma) \overline{a w_{l}}+\gamma c p_{i}$

normalized such that the sum of all actors power $=1$

$\overline{w_{l}}=\frac{w_{i}}{\left(\sum_{j=1}^{n} w_{j}\right)}$

$0 \leq \gamma \leq 1$, by default $\gamma$ set to $(\delta+\theta)$

$c p_{i}(\alpha, \beta)=\sum_{j \neq i}^{n-1}\left(\alpha+\beta c p_{j}\right) t s_{i j}$

In matrix notation

$c p(\alpha, \beta)=\alpha\left(I-\beta t s_{i j}\right)^{-1} t s_{i j} 1$

where " 1 " is a column vector of ones, I is the identity matrix, $\beta=-0.5$ and $\alpha$ is selected so that

$\sum_{i=1}^{n}\left(c p_{i}(\alpha, \beta)\right)^{2}=n^{2}$ 
At this point, each actor makes a decision whether to seek to influence the preferences of another actor, adapt their preferences in response to a peers' influence or do nothing. The joint decisions by $n$ actors lead to a series of proposals, counter-proposals and concessions. The result of these deliberations is an updating of each actor's preferred policy outcome - not their ideal point, but the point that they are either advocating for or willing to accept in a given round of play. The strategic interaction of actors and coalitions of actors continues until actors no longer have an incentive to challenge each other. Mathematically,

(9) Preferences evolve in a series of $t$ rounds via a series of pairwise comparisons between the expected utility to each actor from the proposal of another actor. Each actor begins at their ideal point.

$p_{i, 0}=i p_{i}$

For each pair of actors i and $j$, player i's expected utility from player $j$ 's proposal is the difference between the expected utility to player $i$ from challenging player $j$ 's proposal and the expected utility to player i from not challenging player $j$ 's proposal

$Q_{i}(j)=E_{i}(j)-F_{i}(j)$

$E_{i}(j)=\left[U_{i}\left(p_{i}\right)-U_{i}\left(p_{j}\right)\right]\left[1+2 b_{i j}\left(V_{i}(j)-1\right)\right]$

$F_{i}(j)=U_{i}\left(p_{s q}\right)-\frac{1}{2 n} \sum_{n} U_{i}\left(p_{i: \max }(j)\right)$

$p_{i: \max }(j)=p_{i}: \max \left\{\sum_{k=1}^{n} \overline{w_{k}} b_{i k}\left[U_{k}\left(p_{i}\right)-U_{k}\left(p_{j}\right)\right]\right\}$

$V_{i}(j)=\frac{\overline{w_{l}} s_{i}+\sum_{k \neq i, j}^{n-2} \overline{w_{k}} b_{i k} H_{i j k}}{\overline{w_{l}} s_{i}+\overline{w_{J}} b_{i j}+\sum_{k \neq i, j}^{n-2} \overline{w_{k}} b_{i k}}$

$H_{i j k}=\left\{\begin{array}{l}1 \text { if }\left[U_{k}\left(p_{i}\right)-U_{k}\left(p_{j}\right)\right]>0 \\ 0 \text { else }\end{array}\right.$ 
The relationships between $Q_{i}(j)$ and $Q_{j}(i)$ determines the evolution of $p_{i}$ and $p_{j}$ in a given round of play. Where $Q_{i}(j)<0$ and $Q j(i)<0$, both parties perceive the expected utility to challenging each other's proposal to be less than the expected utility of not challenging and as a result do not offer such a challenge. Analogously, where $Q_{i}(j)>0$ and $Q j(i)>0$, both parties perceive the expected utility to challenging each other's proposal to be greater than the expected utility of not challenging and as a result hold firm to their positions in the hope of succeeding in achieving their policy objective through a "vote" over the policy outcome, a collective decision or a group preference. Where $Q_{i}(j)<0$ but $Q j(i)>0$, actor i perceives the expected utility to challenging actor $\mathrm{j}$ to be less than the expected utility of not challenging that actor but actor $\mathrm{j}$ perceives the utility of a challenge of actor $\mathrm{i}$ to exceed that of not challenging actor $\mathrm{i}$. In such circumstances, actor i's position will unilaterally move towards that of actor $\mathrm{j}$. If $Q j(i)<A B S\left(Q_{i}(j)\right)$, the net expected losses to actor i are greater than the net expected gains to actor $\mathrm{j}$. To avoid these potential losses, actor i concedes to actor $\mathrm{j}$ (i.e., shifts $p_{i}$ to $p_{j}$ ). By contrast, if $Q j(i)>$ $A B S\left(Q_{i}(j)\right)$, the net expected gains to actor $\mathrm{j}$ exceed the net expected losses to actor $\mathrm{i}$ leading actor $\mathrm{i}$ to compromise and shift their preferences towards actor $\mathrm{j}$. Specifically, in this instance actor $\mathrm{i}$ chooses the first point in between their preferred point and that of actor $\mathrm{j}$ that actor $\mathrm{j}$ can credibly threaten to obtain via confrontation. Formally, this point $p_{c}$ must satisfy the credibility constraint.

$$
\begin{aligned}
& C R\left(p_{c}\right)=\frac{\sum_{k=1}^{n} \overline{w_{k}} b_{i k} H_{k}\left(p_{c}\right)}{\sum_{k=1}^{n} \overline{w_{k}} b_{i k}}>0.5 \\
& H_{k}\left(p_{c}\right)=\left\{\begin{array}{c}
1 \text { if }\left[U_{k}\left(p_{c}\right)-U_{k}\left(p_{s q}\right)\right]>0 \\
0 \text { else }
\end{array}\right. \\
& b_{i k}=s_{i} \forall i=k
\end{aligned}
$$

Note that the case of $Q_{i}(j)>0$ but $Q j(i)<0$ is merely a transformation of the case where $Q_{i}(j)<0$ but $Q j(i)>0$ with actor $\mathrm{j}$ altering their preferences instead of actor i. Figure 1 summarizes these 
potential outcomes. The game continues until there are no actor pairs $\mathrm{i}, \mathrm{j}$ where $Q_{i}(j)<0$ but $Q j(i)>0$ at this point the policy outcome, collective decision or group preference is $\frac{\sum_{i=1}^{n} \overline{w_{l}} s_{i} p_{i}}{\sum_{i=1}^{n} \overline{w_{l}} s_{i}}$.

\section{Preliminary Analysis}

At this point it is possible to examine the impact of various assumptions or parameter changes in the decision process on the likelihood of concession, compromise or holding ground. Specifically, I construct 2513 distinct 9-player games which vary systematically in the distribution of preferences, power, issue salience, beliefs of other actor's issue salience, tie strength and tie affect. The strategies chosen by each of the nine actors in each game towards each of their eight peers (a total of 72 pairwise cases for each round of each game or $303,264^{10}$ in total) are subject to categorical regression analysis ${ }^{11}$ in which I examine the impact of specific changes in the processes parameters on the incidence of concession or compromise and a tobit analysis in which I examing the impact on the distance an actor's position moves from their ideal point. The variables that I include in this analysis (See Table 1 for Summary Statistics and a Correlation Matrix) are:

1) The absolute value of the distance between the ideal point of actor $i$ or $\mathrm{j}$ in a given round and that of the median voter;

2) The effective power (the true power multiplied by the issue salience) of actor i, j and of actors perceived to be allied or opposed to I;

3) The accuracy of the beliefs of actor $i$ regarding the issue salience of actor $j$, the allies of $i$ and the opponents of $i$;

4) The strength of ties between actor $i$ and actor $j$

5) The level of affect between actor $i$ and actor $j$

\footnotetext{
${ }^{10}$ In 16 cases, a summation caused a divide by zero or other error in the equation set so the total number of cases examined in the empirical analysis is 303,248 .

${ }^{11}$ The basic results reported below using a probit estimator with clustering of errors by game are robust to the use of a logit or ordinal probit estimator.
} 
6) The power of actor $i$ in the network as a whole treating ties with other well connected actors as a source of power or treating ties with poorly connected actors as a source of power.

The results of preliminary analysis (see Column 1 of Table 2) show that the likelihood of compromise or concession by actor $\mathrm{i}$ towards actor $\mathrm{j}$ in the full sample is

- Increasing in the absolute value of the distance between the preferred policy of actor i and that of the median voter;

- Decreasing in the absolute value of the distance between the preferred policy of actor $\mathrm{j}$ and that of the median voter;

- Decreasing in the effective power of opponents of actor i;

- Increasing in the error in actor i's beliefs regarding the issue salience of actor $\mathrm{j}$ and the opponents of actor i but decreasing in the error in actor i's beliefs regarding the issue salience of the allies of actor $\mathrm{i}$;

- Decreasing in the strength of ties between actor $\mathrm{i}$ and actor $\mathrm{j}$;

- Decreasing in the tie affect between actor $\mathrm{i}$ and actor $\mathrm{j}$;

These aggregate results mask important structural differences based upon the relative preference ordering of actor $\mathrm{i}, \mathrm{j}$ and the position of the median voter. Such structural differences have long been noted within the positive political theory literature (see Krehbiel, 1999 and Holburn \& Vanden Bergh, 2004). Once we allow for structural differences in the coefficient estimates according to whether actor I and $\mathrm{j}$ are on the same side of the median voter (i.e., allies or opponents) and whether, in each of these two cases, actor $\mathrm{i}$ or actor $\mathrm{j}$ is closer to the median voter. Columns 2-7 of Table 2 present a preliminary analysis of the differences in the coefficient estimates between these four regime types. This analysis reveals some new relationships hidden when these separate regimes are combined into a pooled sample.

- The effective power of the allies of $i$ enhance the likelihood of a compromise or concession to an ally but reduce it for an opponent; 
- The effective power of the opponents of $i$ enhance the likelihood of a compromise or concession to an opponent whose preferred point is closer to the median voter than is actor $\mathrm{i}$ but reduces the likelihood for more extreme opponents;

- The error by $i$ in estimating the effective power of $j$ enhances the likelihood of a compromise or a concession for $\mathrm{j}$ 's that are opponents but reduces that likelihood where $\mathrm{j}$ is an ally;

- The error by $\mathrm{i}$ in estimating the effective power of his or her allies increases the likelihood of a compromise or concession to an ally but reduces it for opponents that are closer to the median voter than is actor $i$;

- The negative effect of tie strength on the incidence of compromise or concession is entirely through the case of opponents;

- Tie affect has a positive effect on the incidence of compromise or concession for opponents;

- The centrality of actor i reduces the likelihood of a compromise or concession to an ally but increases the likelihood for an opponent that is closer to the median voter than is actor i;

- The centrality of actor $\mathrm{j}$ increases the likelihood of a compromise or concession if actor $\mathrm{i}$ and $\mathrm{j}$ are allies but reduces that likelihood for opponents.

Table 3 goes one step further and compares the results in each of these regimes for cases in which I allow for the presence of network effects and cases where I do not. The comparison of these cases offers support for the additional computational complexity of the networked or embedded actor process. In each case, prior theoretical or empirical research or our own intuition on political processes conforms more closely to the networked actor process than its autonomous actor counterpart. For example, in the autonomous actor process compromise or concessions are more likely with allies whose preferences are close to the focal actor and opponents whose preferences are as far from the median voter as the focal actor. By contrast, in the network process, compromise is more likely with both allies and opponents that are closer to the median voter. The notion of the median voter being privileged in multiparty negotiations is a longstanding one that need not always hold true but would certainly be expected to manifest itself as a 
mean tendency. The autonomous actor process predicts that compromise or concession is most likely with relatively weak allies and strong opponents whereas the network process suggests it is more likely with weak opponents. Turning to errors in beliefs, the autonomous actor predicts that compromise or concession is more likely with actors whose effective power is overestimated regardless of whether these actors are allies or opponents. The network process, by contrast, leads to a greater incidence of concession or compromise, with allies whose power is underestimated and opponents whose power is overestimated. In the networked process, the strength of the allied coalition is positively associated with the incidence of concession or compromise to an ally and negatively associated with the incidence of concession or compromise to an opponent. Similarly, the strength of the opposing coalition is negatively associated with the incidence of concession or compromise to an opponent. The networked process also captures the tendency to compromise with or concede to opponents with whom you have weak ties; allies or opponents with whom you have strong affect; opponents if you are more central and the opponent is less central; and allies if you are less central and the opponent is more central.

Table 4 presents the results of the tobit analysis for the distance a player moves from their ideal point. Here, the distance of their ideal point from the median voter, the true strength of their opponents as well as overestimations of that strength are associated with greater movement and their own effective power is associated with less movement. In the networked process, centrality and overestimations of one's allies effective power reduces the likelihood of movement and the true effective power of one's allies increases that movement.

\section{Allowing Playcalling to Also Endogenize Issue Salience, Beliefs, Tie Strength, Tie Affect}

The next step in this project will be to make the actors more strategic in so far as they can not only concede, compromise or do nothing but run "plays" or stratagems in an effort to alter other actors' ideal points, issue salience or beliefs, or, the tie strength or tie affect linking any two actors. Several plays are already implicit in the game described above although in a dynamic strategic context they may have 
heretofore neglected consequences. I next turn to describing these plays and their impact summarizing the comprehensive presentation in Kelly (2006) (see also more formal depiction in Table 5 and canonical examples of each play in Table 6). ${ }^{12}$ Following Kelly (2006)'s Playmaker's Table, I present these plays in increasing order of interaction, from the plays designed to "assess" the environment to those that "condition" it and finally plays that directly "engage" that environment.

A "Pass" and a "Pause" follow directly from the preceding game and are thus "detached" from more strategic behavior involve policy concessions or inaction.

Pass. The choice to concede to the proposal of another actor is an explicit strategy that is defensible in many contexts. Deploying a more proactive strategy is a drain of time and resources which the actor may not possess or the probability of a better outcome may be sufficiently small as to "pass" on such an expenditure of effort.

Pause. The choice to do nothing (i.e., neither concede to another actor, compromise with another actor or run a "play") is similarly an explicit strategic choice. It allows for the gathering of more information on the strategies of other actors and the direction of movement in the policy outcome, collective decision or group preference that they are generating while conserving scarce resources. Of course, such a "pause" comes at the expense of the potential upside of a more proactive strategy and may signal weakness to other actors causing them to revise their beliefs regarding your issue salience downwards which may lead them to be more aggressive in future rounds of play.

A "Ping" and a "Trial Balloon" are variations of a policy proposal in the previous game but with the intent of testing other actor's reactions and learning more about their beliefs.

Ping. In reality, actors do not proceed sequentially through pairwise comparisons of their preferred point against all possible actors preferred point and adapt their preferences incrementally

\footnotetext{
${ }^{12}$ As the key insight from the simulation involves the comparative statics (i.e., how a change in a given parameter or set of parameters influences the relative use of a give "play"), the accuracy of the probability levels assigned to each "play" in Table 1 is less important than their relative magnitudes.
} 
according to the outcomes. They choose what proposal to make to whom strategically. They may seek to learn more about other actors' issue salience. Such an effort labeled a "ping" involves a "hint", "oblique" or "elliptical" proposal by actor $i$ with the aim of learning more about other actors' likely strategies which are a function of their issue salience. Pings can, however, be missed due to their low profile.

Trial Balloon. A trial balloon is a more transparent version of a ping and, as a result, is less likely to be missed by other actors. A trial balloon still, however, leaves the actor a means of disavowing the strategy, an escape route from some offered idea or construct. As compared to a ping, there is a greater downside risk in that other actors may learn about the focal actor's issue salience.

The next trio of plays involves deception in the face of a direct attack or momentum towards an unfavorable policy outcome. They "divert" the attention of other actors from their current path.

Deflect. In response to "plays" designed to undermine the power of an actor, that actor can attempt to sidestep the criticism, inspection or attention. The degree of attenuation if the play is successful is a function of the relative power of the attacking and defending actor. In the case of failure, other actors lower their perceptions regarding the issue salience of the actor running a "deflect."

Leak. An opposed actor can attempt to halt or even reverse the momentum towards an unfavorable policy outcome, collective decision or group preference or accelerate the momentum towards a favorable policy outcome, collective decision or group preference by revealing privileged information to a key actor. The "leaking" actor hopes the recipient will spread the information causing other actors to reevaluate their behavior or beliefs based upon the new information. In some cases, the leaked information may have its intended effect but the recipient may expose the "leaker" causing a weakening of ties between the "leaker" of information and non-recipients who resent being left out of confidence. In other cases, the leaker is exposed, the lead of information is unsuccessful and the attempt to leak information causes a reduction in the perceived issue salience of the leaker who is perceived as having no more constructive plays to run. The "leak" is therefore a risky play. 
Red Herring. Another response to unfavorable momentum is a broadcast announcement or symbolic action designed to distract attention or otherwise confuse the attackers and their targets. By feigning a concession or a shift in beliefs, an actor may no longer be targeted with attacks or may otherwise be able to conserve resources. A "red herring" is designed to lead a subset of actors - those who are supporting a change in the status quo policy in a direction away from or even opposite to that of the focal actor - to weaken their beliefs regarding the strength of the focal actor's preferences. The hope is that these actors will lessen their commitment to strategic action assuming that victory is assured. Like a "leak" a red herring is a risky play, that can be ignored or backfire by causing one's opponents and allies to lower their beliefs regarding the strength of the focal actors' preferences or antagonizing one's opponents due to a perception of unethical behavior.

The next four "plays" attempt to frame the issue at hand in a manner that changes or modifies its perceived context so as to alter the preferences of other actors. Each can backfire in a unique manner.

Filter. A filter is a selective retransmission of information that casts a focal actor's position in better light and/or undermines the position of their opponents. It can be a useful strategy for altering preferences of both opponents and allies but can also be exposed leading to a hardening of resolve among opponents and a weakening among allies.

Recast. Like a "filter", a "recast" involves a transmission of information but instead of releasing a segment or subset of information that is strategically chosen to alter preferences a "recast" retransmits information projected by an opponent. The information is, however, altered in emphasis, orientation or order so as to favor the position of the focal actor. If successful, a "recast" not only negates the efforts of the opponent but actually has the same positive effect as a filter. When unsuccessful, a "recast" leads allies to weaken their commitment to the focal actor due to a perception that he or she has little to offer beyond rhetorical battles with their opponent. 
Label. In a "label", the focal actor offers a novel simplification that enhances or augments the focal actor's position by invoking symbols, metaphors, alliteration or other semantic tricks to reshape preferences towards the focal actor, the focal actor's allies or opponents or the policies supported by one side or the other. If successful, it has the same positive benefit as a "filter" or "recast." If unsuccessful, it can be ignored or may even, on account of its personal or self-aggrandizing nature, lead to a hardening of resolve among opponents.

Screen. Like a "label" the goal of a screen is to enhance or augment the focal actor's position. Instead of using a self-concocted "label", however, the "screen" uses a well-understood pre-existing symbol. The symbol is a lower risk play but runs a higher risk than a label of being missed.

The next set of five plays involves stronger efforts to "freeze" opponents' forward momentum. They still fall short of direct engagement but as opposed to merely attempting to change the preferences of other actors they also seek to alter the affect displayed by actors towards each other and/or the strength of ties among actors.

Mirror. A mirror uses an opponent's words, deeds or positions against them to expose contradictions. The goal of a "mirror" is to trigger a reevaluation of the opponent's position and isolate them from their allies. There is a moderate risk, however, that a "mirror" can have the exact opposite effect as intended if misplayed. That is, if the contradictions fail to resonate they can draw attention to the accuser and his or her negative tactics leading to the actors reevaluating the focal actors' position and distancing themselves from the focal actor.

Jam. As opposed to offering new information or symbols that are designed to convey information, a "jam" seeks to disrupt the communication pathways and strategic behavior of opponents. The disruption may take the form of countervailing information or may be physical in nature (e.g., a blockade). If successful, a "jam” weakens the ties among opponents. But, if unsuccessful, it generates resentment hardening the opposition and/or leading to a discomfort among allies. 
Bear Hug. A more positively oriented "freeze" play is the "bear hug" in which the focal actor announces a significant move in their preferred point towards the direction of an opponent in the hope that this "bear hug" will co-opt the affect of ties between the focal actor and third parties thus leading to the perception of a favorable compromise. If unsuccessful, other actors update their beliefs regarding the focal actor's issue salience downward.

Lantern. A "lantern" is based upon an information disclosure but one that deliberately and preemptively discloses flaws or weaknesses in an effort to diminish the impact of a subsequent "mirror", "call out" or "leak" play via which an opponent may make an uncontrolled revelation. The negative information revealed, however, can trigger a negative shift in tie affect.

Disco. A "disco" is a "lantern" run after the release of information. Here, a public concession is combined with an admission of fault in order to allow the focal actor to recover trust and credibility allowing them to proceed unimpeded in the pursuit of their agenda.

As opposed to the preceding plays which are generally designed to alter preferences, tie strength or tie affect of others through some form of subterfuge, the remaining plays are overt actions taken by the focal actor designed to directly engage the opposition.

Challenge. A "challenge" like a "ping" and a "trial balloon" is a simple extension of the policy proposal from the preceding game. Here, the intent is not to learn about the reactions to a change in a preferred point but rather to push forward toward a policy outcome, collective decision or statement of group preference.

Bait. A "bait" is a direct provocative attack on an opponent with the aim of triggering an illadvised challenge. If unsuccessful, the attack is ignored.

Fiat. A "fiat" is the straightforward provision of information or facts designed to sway the preferences of other actors. 
Crowd. A "bear hug" designed to dilute the influence of an opponent is the "crowd" in which the focal actor announces a convergence in their preferred point and that of a prominent powerful opponent in the hope that third parties will not only increase their affect of ties towards the focal actor but also reduce it towards an opponent. If unsuccessful, other actors update their beliefs regarding the focal actor's issue salience downward.

Peacock. A "peacock" is a stronger form of "fiat" in which information is paired with a publicity seeking action. It has a greater upside but also a greater downside risk as the attention seeking nature of the publicity stunt can lead to a reduction in the tie affect between the focal actor and its allies.

Call Out. A “call out” uses an opponent's words, deeds or positions in an emotional direct attack on an opponent with the aim of exposing contradictions. Like a "mirror", the goal of a "call out" is to trigger a reevaluation of the opponent's position and isolate them from their allies. It is, however, a higher risk play as the adversity between the focal actor and the targeted opponent raises questions in other actors' minds about the veracity of the claim. The direct and often judgmental nature of the critique can raise the issue salience for all opponents in a rally around the flag effect and lead to a distancing of allies from the focal actor.

Preempt. A "preempt" is a play that seeks to reverse competitive position by trumping the characteristics or position of another player through swiftness (i.e., action) or stealth (i.e., position).

Draft. A "draft" is a combination of a "crowd" and a "preempt" in which the focal actor announces a convergence in their preferred point and that of a prominent powerful opponent in the hope that third parties will increase their affect of ties towards the focal actor. Unlike a crowd, this initial move is followed by a challenge.

Crazy Ivan. A “crazy Ivan" is a seemingly irrational "challenge" from a position of weakness in the hope that the probabilistic nature of conflict will reveal an unexpected positive surprise particularly as the "challenge" was unexpected and may lead opponents to reevaluate their beliefs. 
The final set of three plays involve the use of counterparties or surrogates. By either creating new network ties or having tied actors act on behalf of the focal actor, the policy outcome may be more favorable than if the focal actor concentrated on independent action.

Partner. A key strategic choice to consider is the possibility of endogenous tie formation as emphasized in the work of Snijders (Burk, Steglich, \& Snijders, 2007, Mercken, Snijders, Candel, Steglich, \& De Vries, 2005, Snijders, Steglich, \& van de Bunt, 2008, Steglich, Snijders, \& Pearson, 2007). By changing the structure of the network, other actors' preferences and issue salience will be altered in future rounds. Thus forging a new dyadic tie is a powerful component of any actors' playbook. The risk, of course, is that the partnership influences the focal actor as opposed to its partner.

Proxy. A related play involves enlisting a counterparty not as a partner but as a proxy. If successful, the counterparty executes the play that maximizes the utility of the focal actor. On account of their perceived independence or power, such a proxy may have a higher likelihood of success than independent action. The downside is that lacking such independence, the proxy is perceived as just that and, furthermore, the proxy may act independently to maximize their own utility.

Plant. The riskiest play for a surrogate is a plant where the surrogate is an opponent who is turned so as to support the position of the focal actor without revealing this fact to other players. The plant can share information, technology or disrupt the opposition without attribution to but at the pleasyre of the focal actor. This strategy is, however, extremely risky with a high likelihood of a rogue plant or exposure which weakens the ties between the focal actor and its allies.

I propose to extend the preliminary agent-based simulation by allowing actors to choose "plays" from the above menu with the aim of improving upon the first-stage policy outcome. In the simplest simulation, each actor chooses a play to run against each other actor assuming that all other actors and the parameters that describe them are unchanged. Subsequently, I will allow each actor to choose a play in a given round assuming that all other actors also choose their best play. By examining the variation in 
strategy sequences across various draws of parameters and rounds of play, I will examine the impact of the same environmental variations considered above in the preliminary analysis of the probability of concession or compromise on the distribution of the choice of influence strategies in each of these simulations. Next, I will examine the distribution of opponent's response strategies. That is, for a given play called by one actor, what is the best response play for another actor and on what does it depend? ${ }^{13}$

\section{Conclusion}

While the dynamic expected utility process of network influence outlined encompasses twentyeight distinct plays, network positional influences on utility, issue salience and power and forwardlooking strategic behavior by utility-maximizing agents, it still necessarily abstracts from the complexities and subtleties of reality for the purpose of analytical tractability. It requires a unidimensional policy space, shared knowledge over the structure of the process and, for the most part, a common information set. It established arbitrary functional forms governing certain key relationships, arbitrary parameter values within those functions and arbitrary probabilities of success and failure for individual plays. It assumes actors can look ahead no more than one period in playing a repeated game. It abstracts away from history, culture, personality types and, most importantly of all, plays motivated by objectives other that utility maximization. ${ }^{14}$ Extensions to this process that loosen these or generalize these assumptions would be welcome but will likely strain the tractability of an already complex decision process.

One straightforward and less onerous extension of the process would recognize that influence games are often sequenced or multi-stage with the identity of the actors and the structure of the policy network varying from one stage to the next. Consider the process of legislation which involves a diffuse network seeking to influence a legislator to introduce a bill, followed by committee deliberation of that bill which includes the committee members and their constituents, followed by legislative deliberation in one or multiple chambers and may require Presidential approval subject to veto, followed by monitoring

\footnotetext{
${ }^{13}$ This step in the analysis parallels Kelly's (2006) playmaker process.

${ }^{14}$ These factors though omitted from the formal model are tentatively included in Kelly's (2006) factors at play.
} 
and implementation including regulatory and judicial oversight. This multi-stage game could be analyzed as a series of inter-connected influence games in which players from each look ahead to the implications of their actions not just on the multi-round game in which they are currently playing but also to the final outcome of the multi-stage process.

While, for the most part, the plays described were constituted and run by one actor on another allowing for each actor to run a play on each other actor, extensions of the process could require each actor to prioritize their play calling and to be able to call a number of plays proportional to their power.

The ultimate virtue of the process is its susceptibility to empirical analysis. While this may seem a surprising claim given the data hurdles involved in populating the social network and parameter values for dozens of relevant actors, just as information technology has allowed for agent-based simulation over this extremely complex process, so too has technology enabled a new form of data collection to test the process. Specifically, information extraction software at the intersection of computer science and linguistics is on the frontier of being able to read unstructured text (e.g., news feeds, press releases, speech transcripts and blogs), consistently identify subject-verb-object triples and code them with respect to affect. For example, if the policy in question is the munificence of the policy environment for a gold mine, a search for all relevant news articles on the mine and on mining in the focal country could be executed on line. The resulting tens of thousands (or more) of news articles could be parsed so as to identify thousands of subject-verb-object triples. The subjects and objects are normalized and clustered. The parser then returns a series of $\mathrm{n} X \mathrm{n}$ matrixes including the number of press mentions of each actor (i.e., autonomously determined power), the ratio of the frequency of discussion of this mine by each actor relative to other mines or other policy issues (i.e., issue salience), the number of press mentions between each dyad (i.e., tie strength), the average affect embedded in the intervening verbs (i.e., tie affect) and the average affect embedded in each verb when the object is the mine in question (i.e., autonomously determined preferences). Until such information extraction technology enters the commercial market, 
human coders can replicate the above process albeit with a substantial loss of speed and increase in marginal cost leading to a substantive decline in time to influence.

While some may object to the formalization of strategies used to sway the opinion of others and label such efforts propaganda, the genie is out of the bottle. Our increased ability to model agents, networks and behavior and hone such processes using heretofore unimaginable quantities of data has created the risk and opportunity of a new era of the engineering of consent. When Edward Bernays popularized the term in the early part of the century, he spoke of the need for practitioners of public relations "to push only those ideas he can respect, and not to promote causes or accept assignments for clients he considers antisocial." (Bernays, 1947: p. 116) The challenge on practitioners today could be even greater. Fortunately, whereas the primary tools employed by Bernays were new forms of mass communication to which large corporations had privileged access due to their deep financial resources, the rapidly collapsing cost of computational power and information today open the door to a more balanced adoption of these techniques. Large corporations will do battle not only with each other but with sophisticated NGOs, social movements and community activists. The implications are on the one hand, a more even playing field, but, on the other hand, a playing field with less coordination and greater potential for abuse. Corporations, politicians and activists will exploit the fear and hope of the public for their own ends as well as for mutual gain. The new technologies enabling the engineering of consent will thus promote the democratization of propaganda for good and for ill. 
$N=303,264$

Mean

Std. Dev

Minimum

Maximum

Preference distance_i_mv

Preference distance___mv

Effective Power_i

Effective Power $\_$j

Effective Power_allies of $i$

Effective Power_opponents of $i$

Error_by 1 in effective power of $j$

Error_by I in effective power of allies

Error_by I in effective power of opponents Tie strength_ij

Tie affect_ij

Centrality_i

Centrality $\_$

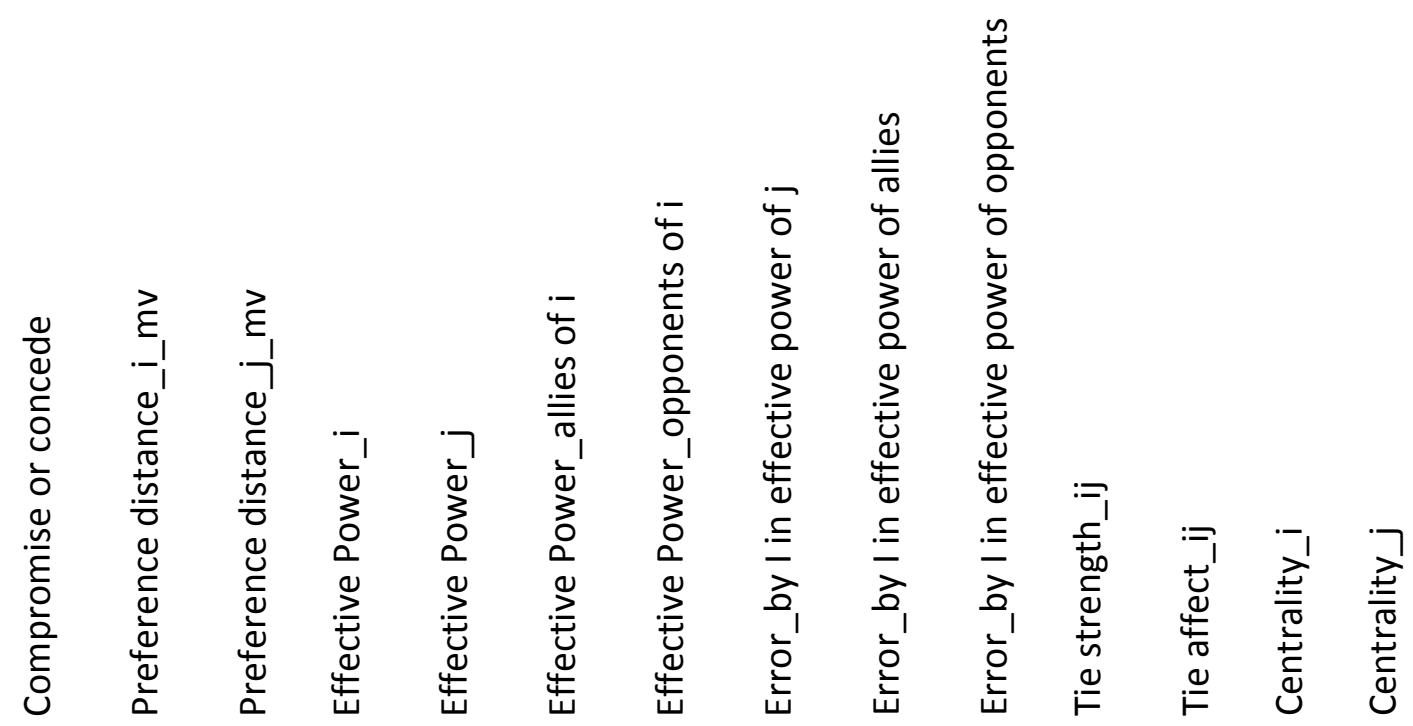

$\begin{array}{llllllllllllll}0.02 & 0.18 & 0.18 & 0.03 & 0.03 & 0.09 & 0.11 & 0.00 & 0.00 & 0.00 & 0.14 & 0.40 & 0.29 & 0.29\end{array}$

$\begin{array}{llllllllllllll}0.14 & 0.12 & 0.12 & 0.03 & 0.03 & 0.08 & 0.10 & 0.02 & 0.04 & 0.08 & 0.13 & 0.43 & 0.11 & 0.11\end{array}$

$\begin{array}{lllllllllllllll}0.00 & 0.00 & 0.00 & 0.00 & 0.00 & 0.00 & 0.00 & -0.16 & -0.38 & -0.44 & 0.00 & -0.96 & 0.00 & 0.00\end{array}$

$\begin{array}{llllllllllllll}1.00 & 0.96 & 0.96 & 0.18 & 0.18 & 0.43 & 0.51 & 0.32 & 0.25 & 0.50 & 0.33 & 1.00 & 0.56 & 0.56\end{array}$

0.34

$-0.05 \quad 0.00$

$\begin{array}{lll}-0.06 & -0.15 & 0.07\end{array}$

$\begin{array}{llll}0.00 & 0.07 & -0.15 & 0.61\end{array}$

$\begin{array}{lllll}-0.01 & -0.03 & 0.09 & 0.74 & 0.65\end{array}$

$\begin{array}{llllll}-0.02 & 0.16 & 0.06 & 0.60 & 0.67 & 0.57\end{array}$

$\begin{array}{lllllll}0.01 & -0.12 & 0.09 & 0.29 & -0.19 & 0.14 & -0.05\end{array}$

$\begin{array}{lllllllll}-0.02 & -0.10 & 0.00 & 0.28 & 0.05 & -0.01 & 0.06 & 0.36\end{array}$

$\begin{array}{lllllllll}0.00 & -0.17 & 0.00 & 0.38 & 0.03 & 0.20 & -0.19 & 0.54 & 0.32\end{array}$

$\begin{array}{llllllllll}-0.04 & -0.06 & -0.06 & 0.02 & 0.02 & -0.04 & 0.02 & -0.01 & -0.02 & -0.01\end{array}$

$\begin{array}{lllllllllll}-0.07 & -0.07 & -0.06 & 0.03 & 0.03 & -0.01 & 0.04 & -0.02 & -0.02 & -0.02 & 0.24\end{array}$

$\begin{array}{llllllllllll}-0.06 & -0.15 & 0.04 & 0.09 & 0.02 & 0.07 & -0.01 & -0.05 & -0.07 & -0.05 & 0.42 & 0.32\end{array}$

$\begin{array}{lllllllllllll}-0.06 & -0.13 & 0.03 & 0.08 & 0.02 & 0.07 & -0.02 & -0.05 & -0.07 & -0.05 & 0.39 & 0.31 & 0.97\end{array}$ 
Table 2: Categorical (Probit) Regression Analysis Varying Relative Preference Positions of $\mathbf{i}$, $j$ and Median Voter

Actors I and $\mathrm{j}$ are allied or opposed

Actor $\mathrm{j}$ closer/further from median voter

Network effects are

Preference distance_i_mv

Preference distance___mv

Effective Power_i

Effective Power $\_$j

Effective Power_allies of $\mathrm{i}$

Effective Power_opponents of $\mathrm{i}$

Error_by I in effective power of $\mathrm{j}$

Error_by I in effective power of allies

Error_by I in effective power of opponents

Tie strength_ij

Tie affect_ij

Centrality_i

Centrality

Constant

Observations

Robust standard errors in parentheses *** $\mathrm{p}<0.01, * * \mathrm{p}<0.05, * \mathrm{p}<0.1$

\begin{tabular}{|c|c|c|c|c|c|c|}
\hline (1) & (2) & (3) & (4) & (5) & (6) & (7) \\
\hline ВОTH & ALLIED & ALLIED & ALLIED & OPPPOSED & OPPPOSED & OPPPOSED \\
\hline ALL & ALL & Closer & Further & ALL & Closer & Further \\
\hline ВOTH & BOTH & ВОТН & BOTH & ВОТН & BOTH & ВОТН \\
\hline $8.360 * * *$ & $7.959 * * *$ & $8.647 * * *$ & & $9.248 * * *$ & $9.187^{* * *}$ & $9.258 * * *$ \\
\hline-0.445 & -0.821 & -0.953 & & -0.368 & -0.377 & -1.109 \\
\hline$-2.525^{* * *}$ & $-6.671 * * *$ & $-8.172 * * *$ & & $-1.483 * * *$ & $-1.016 * * *$ & $-2.284 * * *$ \\
\hline-0.2 & -0.769 & -0.793 & & -0.159 & -0.2 & -0.808 \\
\hline-1.582 & $-6.775 * *$ & $-12.55^{* * *}$ & & $-7.172 * * *$ & $-15.03 * * *$ & $13.14^{* * *}$ \\
\hline-1.024 & -3.197 & -2.625 & & -1.211 & -1.505 & -2.897 \\
\hline-0.628 & $-6.152 * * *$ & $-6.170 * * *$ & & $-3.945 * * *$ & $-3.115^{* *}$ & $-15.89 * * *$ \\
\hline-0.843 & -2.367 & -2.315 & & -1.193 & -1.385 & -2.942 \\
\hline 0.0544 & $4.493^{* * *}$ & $4.356^{* * *}$ & & $-2.031 * * *$ & $-2.204 * * *$ & $-6.169 * * *$ \\
\hline-0.236 & -0.515 & -0.52 & & -0.385 & -0.489 & -1.25 \\
\hline$-1.412^{* * *}$ & -0.789 & 0.0528 & & $1.637^{* * *}$ & $2.454^{* * *}$ & $-3.604 * * *$ \\
\hline-0.264 & -0.745 & -0.75 & & -0.299 & -0.4 & -1.16 \\
\hline $9.990 * * *$ & $-5.107 * * *$ & $-5.608 * * *$ & & $11.49 * * *$ & $13.24^{* * *}$ & $13.00 * * *$ \\
\hline-0.663 & -1.64 & -1.87 & & -0.909 & -1.256 & -2.026 \\
\hline$-0.948 * * *$ & $1.320 * *$ & $1.060 *$ & & $-0.939 * *$ & $-1.110^{*}$ & -0.59 \\
\hline-0.344 & -0.604 & -0.601 & & -0.472 & -0.586 & -1.208 \\
\hline $2.213^{* * *}$ & 0.588 & $1.490 *$ & & $4.224 * * *$ & $4.714^{* * *}$ & $6.198 * * *$ \\
\hline-0.239 & -0.662 & -0.775 & & -0.282 & -0.385 & -0.795 \\
\hline$-1.450 * * *$ & -0.069 & -0.0543 & & $-0.804 * * *$ & $-0.842 * * *$ & -0.176 \\
\hline-0.131 & -0.114 & -0.119 & & -0.131 & -0.138 & -0.441 \\
\hline$-0.239 * * *$ & $-0.421 * * *$ & $-0.375^{* * *}$ & & 0.0364 & $0.0563^{*}$ & -0.0766 \\
\hline-0.0256 & -0.0556 & -0.0578 & & -0.0301 & -0.0338 & -0.0685 \\
\hline 0.584 & $-3.297 * * *$ & $-2.884 * * *$ & & $2.140 * * *$ & $2.612^{* * *}$ & -0.388 \\
\hline-0.363 & -0.562 & -0.587 & & -0.413 & -0.454 & -1.219 \\
\hline-0.399 & $1.753^{* * *}$ & $1.751 * * *$ & & $-2.304 * * *$ & $-2.141 * * *$ & $-2.620 * *$ \\
\hline-0.347 & -0.553 & -0.572 & & -0.384 & -0.428 & -1.136 \\
\hline$-3.738 * * *$ & $-3.403 * * *$ & $-3.686 * * *$ & & $-4.002 * * *$ & $-4.135^{* * *}$ & $-3.037 * * *$ \\
\hline-0.151 & -0.253 & -0.31 & & -0.138 & -0.143 & -0.169 \\
\hline 303248 & 141898 & 38494 & & 161350 & 73252 & 73327 \\
\hline
\end{tabular}


Actors $\mathrm{I}$ and $\mathrm{j}$ are allied or opposed

Actor $\mathrm{j}$ closer/further from median voter

Network effects are

Preference distance_i_mv

Preference distance_j_mv

Effective Power_i

Effective Power

Effective Power_allies of $\mathrm{i}$

Effective Power_opponents of $\mathrm{i}$

Error_by I in effective power of $\mathrm{j}$

Error_by I in effective power of allies

Error_by I in effective power of opponents

Tie strength_ij

Tie affect_ij

Centrality_i

Centrality $\_$

Constant

Observations

Robust standard errors in parentheses *** $p<0.01, * * p<0.05, * p<0.1$

$\begin{array}{lll}\text { ALLIED } & \text { ALLIED } & \text { ALLIED } \\ \text { Closer } & \text { Closer } & \text { Closer } \\ \text { NONE } & \text { ONLY } & \text { ONLY }\end{array}$

$-0.40924 .74 * * * \quad 25.11 * * *$

$$
\begin{array}{lll}
-0.41 & -1.189 & -1.269
\end{array}
$$

$1.624^{* * *}-16.35^{* * *}-16.71^{* * *}$

$\begin{array}{lll}-0.599 & -0.752 & -0.847\end{array}$

$\begin{array}{lll}-10.48 * * * & -0.425 & 1.053\end{array}$

$\begin{array}{lll}-2.37 & -3.498 & -3.315\end{array}$

$\begin{array}{lll}-10.05 * * * & -3.021 & -3.083\end{array}$

$\begin{array}{lll}-2.986 & -4.929 & -4.994\end{array}$

$1.5556 .732 * * * \quad 6.795 * * *$

$\begin{array}{lll}-1.203 & -1.21 & -1.237\end{array}$

$0.309-1.758^{*} \quad-1.794 *$

$\begin{array}{lll}-0.869 & -0.922 & -0.949\end{array}$

$0.472-7.097 * * \quad-7.044 * *$

$\begin{array}{lll}-3.068 & -3.5 & -3.44\end{array}$

$3.558^{* *} \quad 3.948 * * * \quad 3.860^{* * *}$

$\begin{array}{lll}-1.386 & -1.338 & -1.354\end{array}$

$0.9733 .036 * * * \quad 2.936 * * *$

$\begin{array}{lll}-0.765 & -0.751 \quad-0.748\end{array}$

0.0609

-0.435
$0.316 * * *$

$-0.11$

$-3.432 * * *$

$-1.135$

$2.942 * * *$

$-1.142$

$-1.480 * * *-11.20 * * *-11.36^{* * *}$

$\begin{array}{rrr}-0.155 & -0.586 & -0.644 \\ 4393 & 34101 & 34101\end{array}$
(4)

ALLIED

Further

NONE

$7.862 * * *$

$-1.87$

$-3.970 * * *$

$-1.334$

$17.26 * * *$

$-3.287$

$-39.88 * * *$

$-13.69$

1.572

$-1.523$

$-5.224 * * *$

$-1.455$

$24.55^{* * *}$

$-8.245$

$5.941 * *$

$-2.337$

$-7.031 * * *$

$-1.349$

$-2.045^{* * *}$

$-0.236$
(5) (6) (7) OPPPOSED OPPPOSED OPPPOSED $\begin{array}{lll}\text { ALL } & \text { ALL } & \text { ALL } \\ \text { NONE } & \text { ONLY } & \text { ONLY }\end{array}$ NONLY

$\begin{array}{ccc}4.438 * * * & 11.43 * * * & 11.51 * * * \\ -0.486 & -0.152 & -0.171\end{array}$ $1.049 * * * \quad-2.482 * * *-2.626 * * *$ $\begin{array}{lll}-0.277 & -0.125 & -0.133\end{array}$ $-8.478^{* * *}-13.59 * * *-11.40^{* * *}$ $-2.512 \quad-1.507 \quad-1.512$ $4.075 * * * \quad-11.01 * * * \quad-9.935 * * *$ $-1.404 \quad-1.024 \quad-1.071$ $-1.237^{* *}-1.138^{* * *}-1.489 * * *$ $\begin{array}{lll}-0.498 & -0.433 & -0.443\end{array}$ $0.4433 .428 * * * \quad 2.985 * * *$ $\begin{array}{lll}-0.556 & -0.331 \quad-0.326\end{array}$ $8.569 * * * \quad 12.69 * * * \quad 13.34 * * *$ $\begin{array}{lll}-0.89 & -0.968 & -0.999\end{array}$ $\begin{array}{lll}-0.696 & -0.41 & -0.45\end{array}$ $-0.667 \quad-0.549 \quad-0.556$ $1.339 * * * \quad 6.121 * * * \quad 5.780 * * *$ $\begin{array}{llr}-0.512 & -0.345 & -0.347 \\ -0.926 * * *\end{array}$ $-0.159$ $0.0662 *$ $-0.0345$ $2.361 * * *$ $-0.524$ $-4.205 * * *$ $-0.434$

$-3.050 * * *-4.701 * * * \quad-4.069 * * *$ $-0.205-0.0431-0.139$ $\begin{array}{lll}17605 & 143761 \quad 143745\end{array}$
(8)

(9) (10) OPPPOSED OPPPOSED OPPPOSED $\begin{array}{lll}\text { Closer } & \text { Closer } & \text { Closer } \\ \text { NONE } & \text { ONLY } & \text { ONLY }\end{array}$

3.301*** $11.15^{* * *} \quad 11.22^{* * *}$ $\begin{array}{lll}-0.557 & -0.147 & -0.171\end{array}$ $2.599 * * * \quad-1.829 * * *-1.995 * * *$ $\begin{array}{lll}-0.558 & -0.167 \quad-0.176\end{array}$ $-19.39^{* * *}-21.19 * * *-19.27 * * *$ $\begin{array}{lll}-3.443 & -1.831 & -1.824\end{array}$ 5.695*** $-10.09 * * * \quad-9.106 * * *$ $\begin{array}{lll}-1.631 & -1.206 & -1.251\end{array}$ $-1.376^{*}-1.284^{* *}-1.532^{* * *}$ $\begin{array}{lll}-0.775 & -0.536 & -0.541\end{array}$ 1.363** $4.151^{* * *} \quad 3.766^{* * *}$ $\begin{array}{lll}-0.654 & -0.412 \quad-0.406\end{array}$ $10.38^{* * *} \quad 14.26^{* * *} \quad 14.76^{* * *}$

$\begin{array}{lll}-1.671 & -1.049 & -1.08\end{array}$ $\begin{array}{lll}0.603 & -0.834 & -0.806\end{array}$ $\begin{array}{lll}-1.01 & -0.645 & -0.649\end{array}$ $0.9516 .506^{* * *} \quad 6.220 * * *$ $\begin{array}{lll}-0.696 & -0.416 \quad-0.415\end{array}$ $-0.788 * * *$ $-0.167$ $0.0897^{* *}$ $-0.0378$ $2.214 * * *$ $-0.562$ $-4.593 * * *$ $-0.471$ $-2.802^{* * *}-4.611^{* * *}-3.842^{* * *}$ $\begin{array}{lll}-0.246 & -0.0417 & -0.145\end{array}$ $7576 \quad 65684 \quad 65676$
(11) (12) (13) OPPPOSED OPPPOSED OPPPOSED Further Further Further NONE ONLY ONLY

$6.217^{* * *} \quad 16.47^{* * *} \quad 16.58^{* * *}$ $\begin{array}{lll}-1.124 & -2.784 & -2.878\end{array}$

$0.447-7.507^{* * *}-7.543^{* * *}$

$-0.616 \quad-1.588 \quad-1.593$

$1.76131 .56^{* * *} \quad 32.25^{* * *}$

$\begin{array}{lll}-2.787 & -4.266 & -5.204\end{array}$

$-7.064-30.12 * * * \quad-27.96 * * *$

$\begin{array}{lll}-4.856 & -5.564 & -5.752\end{array}$

$-0.392-7.829 * * * \quad-8.095 * * *$

$-1.261 \quad-1.515 \quad-1.594$

$-4.213 * * \quad-7.049 * * *-7.442 * * *$

$\begin{array}{lll}-1.87 & -1.798 \quad-2.592\end{array}$ 14.96*** 6.821* 7.905**

$\begin{array}{lll}-1.899 & -3.714 & -3.703\end{array}$

$\begin{array}{lll}-4.840 * * * & 2.808 & 2.11\end{array}$

$\begin{array}{lll}-1.626 & -2.134 & -2.211\end{array}$

$0.07888 .142^{* * *} \quad 8.146^{* * *}$

$\begin{array}{lll}-1.254 & -0.955 & -0.989\end{array}$

$-1.051$

$-0.683$

$-0.0967$

$-0.0838$

1.501

$-1.959$

0.429

$-1.695$

$-3.128 * * *-4.584 * * *-5.122 * * *$

$\begin{array}{lll}-0.196 & -0.769 & -1.314\end{array}$

$\begin{array}{lll}7420 & 65915 \quad 65907\end{array}$ 
Table 4: Tobit Analysis of Extent of Movement of an Actor's Position from their Ideal Point

\begin{tabular}{|c|c|c|c|c|c|c|}
\hline & ALL & ALL & AUT & NET & NET & NET \\
\hline \multirow{2}{*}{ Preference Distance_i } & $0.673^{* * *}$ & $0.668^{* * *}$ & $0.542^{* * *}$ & $0.719 * * *$ & $0.634^{* * *}$ & $0.640 * * *$ \\
\hline & -0.011 & -0.011 & -0.047 & -0.005 & -0.008 & -0.008 \\
\hline \multirow[t]{2}{*}{ Effective Power_i } & $-1.785 * * *$ & $-1.742 * * *$ & $-1.732 * * *$ & $-1.975 * * *$ & $-1.346 * * *$ & $-1.336 * * *$ \\
\hline & -0.129 & -0.129 & -0.335 & -0.060 & -0.074 & -0.074 \\
\hline \multirow[t]{2}{*}{ Effective Power_allies of $i$} & $0.0915^{* * *}$ & $0.0782 * * *$ & -0.06 & $0.105^{* * *}$ & $0.0671 * * *$ & $0.0375^{* *}$ \\
\hline & -0.016 & -0.016 & -0.067 & -0.013 & -0.015 & -0.015 \\
\hline \multirow[t]{2}{*}{ Effective Power_opponents of $i$} & $0.297^{* * *}$ & $0.298^{* * *}$ & $0.379 * * *$ & $0.320^{* * *}$ & $0.225^{* * *}$ & $0.245^{* * *}$ \\
\hline & -0.024 & -0.025 & -0.081 & -0.010 & -0.011 & -0.011 \\
\hline \multirow[t]{2}{*}{ Error_of I on allies } & $-0.0968 * * *$ & $*-0.104 * * *$ & 0.05 & $-0.0872 * * *$ & $*-0.114 * * *$ & $-0.134 * * *$ \\
\hline & -0.025 & -0.025 & -0.102 & -0.022 & -0.024 & -0.024 \\
\hline \multirow[t]{2}{*}{ Error_or I on opponents } & $0.244 * * *$ & $0.242 * * *$ & $0.368 * * *$ & $0.268 * * *$ & $0.147 * * *$ & $0.163 * * *$ \\
\hline & -0.019 & -0.019 & -0.079 & -0.011 & -0.012 & -0.012 \\
\hline \multirow[t]{2}{*}{ Centrality_i (Beta $=0.5)$} & $-0.182^{* * *}$ & & & & $-0.561 * * *$ & \\
\hline & -0.014 & & & & -0.023 & \\
\hline \multirow[t]{2}{*}{ Centrality_i (Beta $=-0.5)$} & & $-0.182 * * *$ & & & & $-0.434 * * *$ \\
\hline & & -0.013 & & & & -0.019 \\
\hline \multirow[t]{2}{*}{ Constant } & $0.143^{* * *}$ & $0.143^{* * *}$ & $0.143^{* * *}$ & $0.0782 * * *$ & $0.276^{* * *}$ & $0.232 * * *$ \\
\hline & -0.006 & -0.006 & -0.015 & -0.001 & -0.009 & -0.008 \\
\hline Observations & 37908 & 37908 & 4168 & 33740 & 33740 & 33740 \\
\hline$* * * p<0.01, * * p<0.05, * p<0.1$ & & & & & & \\
\hline
\end{tabular}


Table 5: Potential Impacts of Influence "Plays"

\begin{tabular}{|c|c|c|c|c|c|c|}
\hline Play & $\frac{\text { Prob }}{(\mathrm{s})}$ & $\frac{\text { Prob }}{\text { (i) }}$ & $\frac{\text { Prob }}{\text { (f) }}$ & Successful Outcome & $\begin{array}{l}\text { Intermediate } \\
\text { Outcome }\end{array}$ & Failure Outcome \\
\hline Pass & $100 \%$ & $0 \%$ & $0 \%$ & $p_{i, t}=p_{j, t-1}$ & $\mathrm{n} / \mathrm{a}$ & $\mathrm{n} / \mathrm{a}$ \\
\hline Pause & $67 \%$ & $0 \%$ & $33 \%$ & No change & $\mathrm{n} / \mathrm{a}$ & $b_{j i, t}=0.9 b_{j i, t-1} \forall \mathrm{j}$ \\
\hline Ping & $67 \%$ & $0 \%$ & $33 \%$ & $\begin{array}{l}p_{i, t}=5\left(p_{i, t-1}-p_{i, t-2}\right)+p_{i, t-1} \\
b_{i j, t}=\left\{\begin{array}{l}b_{i j, t-1}+\left(0.1\left(b_{i j, t}-a s_{j}\right)\right) \text { if } b_{i j, t}>a s_{j} \\
b_{i j, t-1}+\left(0.1\left(a s_{j}-b_{i j, t}\right)\right) \text { if } b_{i j, t}<a s_{j} \\
b_{i j, t-1} \text { if } b_{i j, t}=a s_{j}\end{array}\right.\end{array}$ & $\mathrm{n} / \mathrm{a}$ & No change \\
\hline $\begin{array}{l}\text { Trial } \\
\text { Balloon }\end{array}$ & $33 \%$ & $33 \%$ & $33 \%$ & $\begin{array}{l}p_{i, t}=5\left(p_{i, t-1}-p_{i, t-2}\right)+p_{i, t-1} \\
b_{i j, t+1}=\left\{\begin{array}{l}b_{i j, t}+\left(0.1\left(b_{i j, t}-a s_{j}\right)\right) \text { if } b_{i j, t}>a s_{j} \\
b_{i j, t}+\left(0.1\left(a s_{j}-b_{i j, t}\right)\right) \text { if } b_{i j, t}<a s_{j} \\
b_{i j, t} \text { if } b_{i j, t}=a s_{j}\end{array}\right.\end{array}$ & $\mathrm{n} / \mathrm{a}$ & $b_{j i, t}=\left\{\begin{array}{l}b_{j i, t-1}+\left(0.1\left(b_{j i, t}-a s_{i}\right)\right) \text { if } b_{j i, t}>a s_{i} \\
b_{j i, t-1}+\left(0.1\left(a s_{i}-b_{j i, t}\right)\right) \text { if } b_{j i, t}<a s_{i} \\
b_{j i, t-1} \text { if } b_{j i, t}=a s_{i}\end{array}\right.$ \\
\hline Deflect & $67 \%$ & $0 \%$ & $33 \%$ & $\begin{array}{l}\text { Outcome of actor j's "mirror", "bait", "call out", } \\
\text { "label" or "challenge" best outcome in previous } \\
\text { period reduced by }\left(1-\left(\frac{\overline{w_{l}}}{\bar{w}_{j}}\right) \text { iff } s_{i}>s_{j}\right.\end{array}$ & $\mathrm{n} / \mathrm{a}$ & $b_{j i, t}=0.9 b_{j i, t-1} \forall \mathrm{j}$ \\
\hline Leak & $33 \%$ & $33 \%$ & $33 \%$ & $\begin{array}{l}p_{j, t}=p_{j, t-1}+0.1\left(p_{i, t-1}-p_{j, t-1}\right) \\
p_{k, t}=p_{k, t-1}+0.1 t s_{j k}\left(p_{i, t-1}-p_{k, t-1}\right)\end{array}$ & $\begin{array}{l}p_{j, t}=p_{j, t-1}+0.1\left(p_{i, t-1}-p_{j, t-1}\right) \\
p_{k, t}=p_{k, t-1}+0.1 t s_{j k}\left(p_{i, t-1}-p_{k, t-1}\right) \\
t s_{i k, t}=0.90\left(t s_{i k, t-1}\right) \quad \forall k \neq j \\
t a_{i j, t}=t a_{i j, t-1}-0.5\end{array}$ & $\begin{array}{l}t s_{i k, t}=0.90\left(t s_{i k, t-1}\right) \quad \forall k \neq j \\
t a_{i j, t}=t a_{i j, t-1}-0.5 \\
b_{j i, t}=0.9 b_{j i, t-1} \forall \mathrm{j}\end{array}$ \\
\hline \begin{tabular}{|l|} 
Red \\
Herring
\end{tabular} & $33 \%$ & $33 \%$ & $33 \%$ & $\begin{array}{l}b_{j i, t}=0.8 b_{i j, t-1} \forall \mathrm{j}_{\mathrm{o}} \\
\mathrm{j}_{\mathrm{o}} \exists p_{j, t}>p_{s q}>p_{i, t} \text { or } p_{j, t}<p_{s q}<p_{i, t} \\
\mathrm{j}_{\mathrm{a}} \exists p_{j, t}>p_{i, t}>p_{s q} \text { or } p_{j, t}<p_{i, t}<p_{s q}\end{array}$ & $b_{j i, t+1}=0.9 b_{j i, t} \forall \mathrm{j}$ & $\begin{array}{l}t s_{i k, t}=0.90\left(t s_{i k, t-1}\right) \quad \forall k \neq j \\
t a_{i j, t}=t a_{i j, t-1}-0.5 \\
b_{j i, t+1}=0.9 b_{j i, t} \forall \mathrm{j}\end{array}$ \\
\hline Filter & $67 \%$ & $0 \%$ & $33 \%$ & $p_{j, t}=p_{j, t-1}+0.1\left(p_{i, t-1}-p_{j, t-1}\right) \forall \mathrm{j}$ & $\mathrm{n} / \mathrm{a}$ & $\begin{aligned} t s_{i j, t} & =0.90\left(t s_{i j, t-1}\right) \quad \forall \mathrm{j}_{\mathrm{a}} \\
t s_{i j, t} & =1.10\left(t s_{i j, t-1}\right) \forall \mathrm{j}_{\mathrm{o}}\end{aligned}$ \\
\hline Recast & $67 \%$ & $0 \%$ & $33 \%$ & $p_{j, t}=p_{j, t-1}+0.1\left(p_{i, t-1}-p_{j, t-1}\right) \forall \mathrm{j}$ & $\mathrm{n} / \mathrm{a}$ & $t s_{i j, t}=0.80\left(t s_{i j, t-1}\right) \forall \mathrm{j}_{\mathrm{a}}$ \\
\hline Label & $67 \%$ & $0 \%$ & $33 \%$ & $p_{j, t}=p_{j, t-1}+0.1\left(p_{i, t-1}-p_{j, t-1}\right) \forall \mathrm{j}$ & $\mathrm{n} / \mathrm{a}$ & $a s_{j, t}=1.20\left(a s_{j, t-1}\right) \forall \mathrm{j}_{o}$ \\
\hline Screen & $33 \%$ & $33 \%$ & $33 \%$ & $p_{j, t}=p_{j, t-1}+0.1\left(p_{i, t-1}-p_{j, t-1}\right) \forall \mathrm{j}$ & No change & $\begin{array}{l}a s_{j, t}=1.10\left(a s_{j, t-1}\right) \forall \mathrm{j}_{\mathrm{o}} \\
a s_{j, t}=0.90\left(a s_{j, t-1}\right) \forall \mathrm{j}_{\mathrm{a}}\end{array}$ \\
\hline Mirror & $50 \%$ & $0 \%$ & $50 \%$ & $\begin{array}{l}\text { Outcome of actor j's "call out" or "leak" } \\
\text { best outcome in subsequent period reduced by } \\
\left(1-\left(\frac{\overline{w_{l}}}{\overline{w_{J}}}\right)\right) \text { iff } s_{i}>s_{j}\end{array}$ & $\mathrm{n} / \mathrm{a}$ & $a s_{j, t}=1.10\left(a s_{j, t-1}\right) \forall \mathrm{j}_{\mathrm{o}}$ \\
\hline Jam & $50 \%$ & $0 \%$ & $50 \%$ & $t s_{i k, t}=0.80\left(t s_{i k, t-1}\right) \forall \mathrm{j}_{\mathrm{o}}$ & $\mathrm{n} / \mathrm{a}$ & $\begin{array}{l}t s_{i k, t}=1.10\left(t s_{i k, t-1}\right) \forall \mathrm{j}_{\mathrm{o}} \\
t a_{i j, t}=t a_{i j, t-1}-0.1 \forall \mathrm{j}_{\mathrm{a}}\end{array}$ \\
\hline
\end{tabular}




\begin{tabular}{|c|c|c|c|c|c|c|}
\hline Bear Hug & $67 \%$ & $0 \%$ & $33 \%$ & $\begin{array}{l}p_{i, t}=p_{j, t} \forall \mathrm{j}_{\mathrm{o}}: \max \left(\overline{a w_{J o}}\right) \\
t a_{i j, t}=t a_{i j, t-1}+0.1 \forall \mathrm{j}_{\mathrm{o}}\end{array}$ & $\mathrm{n} / \mathrm{a}$ & $b_{j i, t}=0.9 b_{j i, t-1} \forall \mathrm{j}$ \\
\hline Lantern & $50 \%$ & $0 \%$ & $50 \%$ & $\begin{array}{l}p_{j, t}=p_{j, t-1}+0.1\left(p_{i, t-1}-p_{j, t-1}\right) \forall \mathrm{j} \\
t a_{j k, t}=t a_{j k, t-1}+0.1 \forall \mathrm{j}_{\mathrm{a}}, \mathrm{k}_{\mathrm{a}}\end{array}$ & $\mathrm{n} / \mathrm{a}$ & $t a_{i j, t}=t a_{i j, t-1}-0.1 \forall \mathrm{j}$ \\
\hline Disco & $33 \%$ & $0 \%$ & $67 \%$ & $\begin{array}{l}p_{i, t}=p_{i, t-1}+0.2\left(p_{i, t-1}-p_{j, t-1}\right) \forall \mathrm{j} \\
t a_{i j, t}=t a_{i j, t-1}+0.2 \forall \mathrm{j}_{\mathrm{a}}, \mathrm{k}_{\mathrm{a}}\end{array}$ & $\mathrm{n} / \mathrm{a}$ & $\begin{array}{l}b_{j i, t}=0.9 b_{j i, t-1} \forall \mathrm{j} \\
t a_{i j, t}=t a_{i j, t-1}-0.1 \forall \mathrm{j}\end{array}$ \\
\hline Challenge & $100 \%$ & $0 \%$ & $0 \%$ & $\begin{array}{l}\text { Call for a policy outcome, collective decision } \\
\text { or } \\
\text { group preference, other actors can still run a } \\
\text { play }\end{array}$ & $\mathrm{n} / \mathrm{a}$ & $\mathrm{n} / \mathrm{a}$ \\
\hline Bait & $50 \%$ & $0 \%$ & $50 \%$ & $\begin{array}{l}\text { Call for an immediate policy outcome, } \\
\text { collective } \\
\text { decision or group preference }\end{array}$ & $\mathrm{n} / \mathrm{a}$ & No change \\
\hline Fiat & $67 \%$ & $0 \%$ & $33 \%$ & $p_{j, t}=p_{j, t-1}+0.05\left(p_{i, t-1}-p_{j, t-1}\right) \forall \mathrm{j}$ & $\mathrm{n} / \mathrm{a}$ & No change \\
\hline Crowd & $50 \%$ & $0 \%$ & $50 \%$ & $\begin{array}{l}p_{i, t}=p_{j, t} \forall \mathrm{j}_{\mathrm{o}}: \max \left(\overline{a w_{J_{o}}}\right) \\
t a_{i j, t}=t a_{i j, t-1}+0.1 \forall \mathrm{j}_{\mathrm{o}} \\
t a_{j k, t}=t a_{j k, t-1}-0.1 \forall \mathrm{j}_{\mathrm{o}}: \max \left(\overline{a w_{J_{o}}}\right)\end{array}$ & $\mathrm{n} / \mathrm{a}$ & $b_{j i, t}=0.9 b_{j i, t-1} \forall \mathrm{j}$ \\
\hline Peacock & $33 \%$ & $33 \%$ & $33 \%$ & $p_{j, t}=p_{j, t-1}+0.10\left(p_{i, t-1}-p_{j, t-1}\right) \forall \mathrm{j}$ & No change & $t a_{i j, t}=t a_{i j, t-1}-0.1 \forall \mathrm{j}_{\mathrm{a}}$ \\
\hline Call Out & $33 \%$ & $33 \%$ & $33 \%$ & $\begin{array}{l}p_{j, t}=p_{j, t-1}+0.2\left(p_{i, t-1}-p_{j, t-1}\right) \forall \mathrm{j} \\
t a_{j k, t}=t a_{j k, t-1}-0.2 \forall \mathrm{j}_{\mathrm{o}}, \mathrm{k}_{\mathrm{o}}\end{array}$ & $\begin{array}{l}a s_{j, t}=1.10\left(a s_{j, t-1}\right) \\
\forall \mathrm{j}_{\mathrm{o}}\end{array}$ & $\begin{array}{l}a s_{j, t}=1.10\left(a s_{j, t-1}\right) \forall \mathrm{j}_{\mathrm{o}} \\
t s_{i j, t}=0.80\left(t s_{i j, t-1}\right) \forall \mathrm{j}_{\mathrm{a}}\end{array}$ \\
\hline Preempt & $33 \%$ & $33 \%$ & $33 \%$ & $\begin{array}{l}p_{j, t}=p_{j, t-1}+0.05\left(p_{i, t-1}-p_{j, t-1}\right) \forall \mathrm{j} \\
t a_{i j, t}=t a_{i j, t-1}+0.1 \forall \mathrm{j}_{\mathrm{o}} \\
\text { Followed by a challenge }\end{array}$ & No change & $t a_{i j, t}=t a_{i j, t-1}-0.1 \forall \mathrm{j}_{\mathrm{a}}$ \\
\hline Draft & $50 \%$ & $0 \%$ & $50 \%$ & $\begin{array}{l}p_{i, t}=p_{j, t} \forall \mathrm{j}_{\mathrm{o}}: \max \left(\overline{a w_{J o}}\right) \\
t a_{i j, t}=t a_{i j, t-1}+0.1 \forall \mathrm{j} \\
t a_{j k, t}=t a_{j k, t-1}-0.1 \forall \mathrm{j}_{\mathrm{o}}: \max \left(\overline{a w_{J o}}\right) \\
\text { Followed by a challenge }\end{array}$ & $\mathrm{n} / \mathrm{a}$ & $b_{j i, t}=0.9 b_{j i, t-1} \forall \mathrm{j}$ \\
\hline \begin{tabular}{|l|} 
Crazy \\
Ivan
\end{tabular} & $10 \%$ & $0 \%$ & $90 \%$ & $\begin{array}{l}b_{j i, t}=1.00 \forall \mathrm{j} \\
\text { Followed by a challenge }\end{array}$ & $\mathrm{n} / \mathrm{a}$ & $t s_{i j, t}=0.5 t s_{i j, t-1} \forall \mathrm{j}_{\mathrm{a}}$ \\
\hline Partner & $50 \%$ & $0 \%$ & $50 \%$ & $\begin{array}{l}t s_{i j, t}=\operatorname{Average}\left(t s_{i j, t-1}\right) \\
t a_{i j, t}=\operatorname{Average}\left(t a_{i j, t-1}\right)\end{array}$ & $\mathrm{n} / \mathrm{a}$ & $\begin{array}{l}t s_{i j, t}=\text { Average }\left(t s_{i j, t-1}\right) \\
t a_{i j, t}=\text { Average }\left(t a_{i j, t-1}\right) \\
p_{i, t}=p_{i, t-1}+0.5\left(p_{i, t-1}-p_{j, t-1}\right)\end{array}$ \\
\hline Plant & $33 \%$ & $0 \%$ & $67 \%$ & Actor $j_{o}$ chooses play that maximizes $i$ 's utility & $n / a$ & $\begin{array}{l}\text { Actor } j_{o} \text { chooses play that maximizes their utility and } t a_{i j, t}=t a_{i j, t-1}- \\
0.2 \forall \mathrm{j}_{\mathrm{a}}\end{array}$ \\
\hline
\end{tabular}




\begin{tabular}{|c|c|}
\hline Play & Examples \\
\hline Pass & $\begin{array}{l}\text { - IBM PCs In December 2004, IBM sold its once vaunted PC business to China-based Lenovo Group Ltd., giving Big Blue room to focus its resources on higher } \\
\text { margin businesses with greater strategic value. } \\
\text { - Cuban withdrawal October 28, 1962: Soviet radio reads USSR premier Nikita Kruschev's letter to U.S. President John F. Kennedy, announcing the immediate } \\
\text { dismantling and withdrawal of missiles from Cuba. } \\
\text { - Dave Chappelle In May 2005, Comedian Dave Chappelle, host of Comedy Central's highly rated Chappelles' Show, walked away in the show's third season, } \\
\text { leaving stunned fans and a \$50 million contract hanging. Months later, he cited stress and subpar quality of work as the reasons for his exit. }\end{array}$ \\
\hline Pause & $\begin{array}{l}\text { - Chernobyl On April 26, 1986, in the southwest regions of the former Soviet Union, the fourth reactor of the Chernobyl nuclear power plant caught fire, exploded, } \\
\text { and spewed radioactive waste across an entire civilized hemisphere. Millions were caught in the dispersing radioactive cloud and hundreds dies while Soviet } \\
\text { officials scampered to suppress panic and save face. Two interminable days later, a stone-faced Soviet broadcaster read a forty-three word statement confirming } \\
\text { the devastation. } \\
\text { Euronext In 2001, when rumors that the London-based exchange LIFE was on the block, it took only a few news cycles for British tabloids to warn that the } \\
\text { trading network must be kept for the sake of national prestige. But one bidder, and LIFFE's ultimate acquirer, Euronext, didn't bite. It bypasses the handwringers } \\
\text { and worked its case with decisionmakers directly. } \\
\text { Winston Churchill In a crucial meeting with the sitting prime minister, Neville Chamberlain, Winston Churchill uncharacteristically held his tongue as his rival, } \\
\text { Lord Halifax, prattled too long and too much about the difficulties of the prime minister's post. The position-and the weight or history--went to Churchill. }\end{array}$ \\
\hline Ping & $\begin{array}{l}\text { - Gambling Power tables are often punctuated with Pings, the side comments of trash-talking card sharks. Players slightly rib their opponents to watch for their } \\
\text { - } \quad \text { Greetions. } \\
\text { plodding forty-three-hundred-word talk - irrational exuberance. It chilled the market and planted a seed of caution. } \\
\text { - The Sopranos Livia Soprano coolly suggested to her brother-in-law, Uncle Jun, that her own son, Tony Soprano, should get whacked. "Tony's running the show } \\
\text { behind your back, and did I mention he's in therapy? God knows what he's telling that shrink." This is all to say, Assert yourself now, you wimp, or Tony will } \\
\text { take you down. }\end{array}$ \\
\hline $\begin{array}{l}\text { Trial } \\
\text { Balloon }\end{array}$ & $\begin{array}{l}\text { - Disney In 2005, Disney teamed with Apple to test the burgeoning marketplace for portable iPod video. With its cache of popular mainstream movies, animation } \\
\text { and TV shows, Disney saw that the time to jump in was sooner, not later. } \\
\text { - Professor Activist In February 2005, hoping to remove the rogue professor and so-called terrorist sympathizer Ward Churchill from his post at the University of } \\
\text { Colorado, university regents leaked word or a six- to seven- figure package. } \\
\text { - Comic books The Maryland Department of Education in } 2005 \text { used the rebirth of comic books to create a reading on-ramp for slow-to-read students. }\end{array}$ \\
\hline Deflect & $\begin{array}{l}\text { - Steroids In 2005, when home-run slugger Mark McGwire was summoned to Washington to reveal under oath what he knew about steroids in baseball, Big Mac } \\
\text { said to the incredulous representatives, "I'm not here to talk about the past. I'm here to be positive about this subject." } \\
\text { - Palme and Rove When rumors swirled that White House deputy chief of staff Karl Rove had outed CIA operative Valerie Palme, White House press secretary } \\
\text { Scott McLellan called the suggestion of Rove's involvement ridiculous and promised that a White House leaker would be a fired White House leaker. Two years } \\
\text { later, when Rove did come under investigation by the Justice Department, McLellan ducked a question from a howling White House press corps, saying guiltlessly } \\
\text { “...we're not going to [comment] on an ongoing criminal investigation from this podium.” } \\
\text { - New Coke At a } 1985 \text { unveiling of New Coke, Coke executives were chided about Pepsi's success in forcing the switch. "To what extent are you introducing this } \\
\text { produce to meet the Pepsi Challenge?" reporters probed. "Oh, gosh, no. The Pepsi Challenge? When did it happen? Said the tongue-in-cheek Coke chairman } \\
\text { Robert Goizueta. }\end{array}$ \\
\hline Leak & $\begin{array}{l}\text { - Deep Throat It was the FBI's number two man, Mark Felt, who leaked crucial information to Washington Post reporter Bob Woodward to help expose the } \\
\text { Watergate scandal and end Richard Nixon's presidency. } \\
\text { - } \\
\text { JFK Leak In } 1961 \text { an official of the Kennedy administration leaked information that proved the U.S.'s nuclear advantage over the USSR. Kruschev countered the } \\
\text { - } \\
\text { Holocaust In 1942, Samuel Sydney Silverman, a member of British Parliament, learned of Hitler's plan to anhiliate the Jews of German-occupied Europe. H } \\
\text { bypassed channels and shot the information to the American Jewish leader Stephen Wise, who, in turn forced Roosevelt to face the horrible truth. }\end{array}$ \\
\hline
\end{tabular}




\begin{tabular}{|l|l|}
\hline Play & Examples \\
\hline Proxy & $\begin{array}{l}\text { combo and the band's new track "Vertigo." The marriage also helped the mutually advantageous downloading business model. } \\
\text { Tsunami Relief In the aftermath of the 2004 Indian Ocean tsunami, former presidents Bush and Clinton combined forces in a bipartisan call for Amercians to } \\
\text { donate relief funds to the devastated and displaced. }\end{array}$ \\
\hline $\begin{array}{l}\text { Swift Boats During the } 2004 \text { presidential campaign, John Kerry enlisted the help of his former Swift Boat crewmen, who testified to the senator's wartime } \\
\text { bravery. Not to be outdone, the GOP found its own Proxies, so-called "Swift Boat Veterans for Truth" who countered with a different story. } \\
\text { Tiger Woods In 2001, Nike signed golfing superstar Tiger Woods to a huge endorsement contract, rumored at \$100 million over five years-just enough to get } \\
\text { Tiger's support of Nike and to pump sales of Nike sports gear. }\end{array}$ \\
\hline $\begin{array}{l}\text { Gay Marriage When in 2004 San Francisco Mayor Gavin Newsom ordered City Hall to open its doors to gay and lesbian couples seeking marriage licenses, the } \\
\text { young politician was acting in the interests of his constituents and their cries for same-sex marriage. }\end{array}$ \\
\hline $\begin{array}{l}\text { PETA From 2002 to 2003, an activist for PETA (People for the Ethical Treatment of Animals), worked inside the testing labs for Procter \& Gamble Iams pet food } \\
\text { division and chronicled the lab's work on animals. Armed with their insider's accounts, PETA officials later charged violations of animal rights through twenty- } \\
\text { seven destroyed "research associates" and other inhumane practices such as debarking. } \\
\text { Rumsfeld In December 2004, during a "Town Hall Meeting" with U.S. troops in Iraq, U.S. defense secretary Donald Rumsfeld was put to the test when a national } \\
\text { guardsman asked a question about subpar vehicle armor. Later, an embedded reporter from the Chatanooga Times Free Press admitted to coaxing the unwitting } \\
\text { solider to fire the rehearsed question. } \\
\text { Evel Knievel In 1967, when daredevil Evel Knievel was getting his motorcycle-jumping career off the ground, he placed calls to the Las Vegas casino Caesars } \\
\text { Palace CEO Jay Sarno, posing each time as a reporter. "So tell me about this Evel Knievel's plan to jump your fountains?" he probed. Sarno knew nothing but, } \\
\text { soon enough, wanted to meet Even and got the show on the road. }\end{array}$ \\
\hline
\end{tabular}

Source: Reproduced from Kelly (2006) 
Figure 1: Expected Utility and Preference Evolution

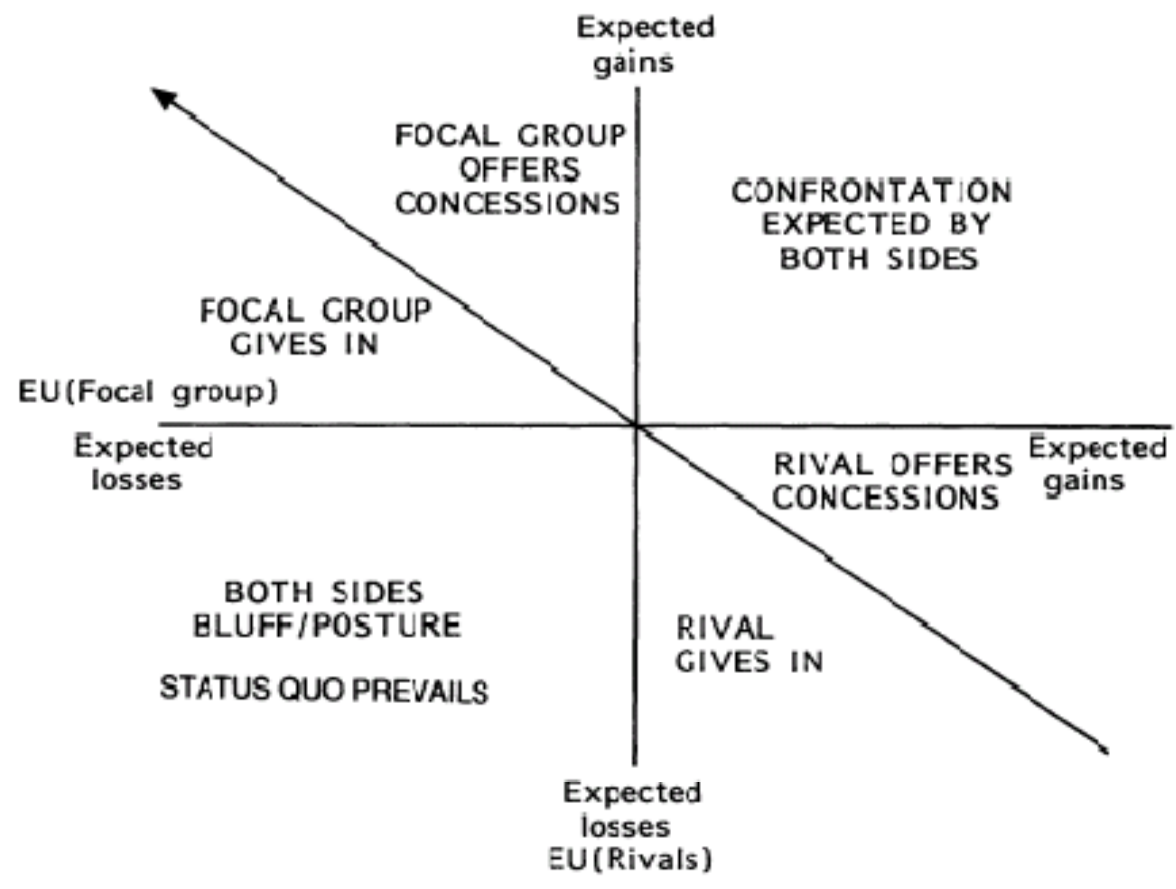

Source: Reproduced from De Mesquita and Organski (1992) 


\section{REFERENCES}

Acemoglu, Daron \& James A. Robinson. 2006. Economic origins of dictatorship and democracy. Cambridge ; New York: Cambridge University Press.

Allas, Tera \& Nikos Georgiades. 2001. New Tools for Negotiators. McKinsey Quarterly, 2001(2): 86-91.

Barley, S. R. 2007. Corporations, democracy, and the public good. Journal of Management Inquiry, 16(3): 201-15.

Bernays, Edward L. 1947. The Engineering of Consent. Annals of the American Academy of Political and Social Science, 250: 113-20.

Bonacich, P. 1987. Power and Centrality - a Family of Measures. American Journal of Sociology, 92(5): 1170-82.

Bonacich, Phil. 1987. Power and Centrality: A Family of Measures. American Journal of Sociology, 92: 1170-82.

Borgatti, S. P. 2006. Identifying Sets of Key Players in a Network. Computational, Mathematical and Organizational Theory, 12(1): 21-34.

Burk, W. J., C. E. G. Steglich, \& A. B. Snijders. 2007. Beyond dyadic interdependence: Actor-oriented models for co-evolving social networks and individual behaviors. International Journal of Behavioral Development, 31(4): 397-404.

Burt, R. 1992. Structural Holes: The Social Structure of Competition. Cambridge: Harvard University Press.

Burt, R. S. 2004. Structural holes and good ideas. American Journal of Sociology, 110(2): 349-99.

Burt, Ronald. 1997. The Contingent Value of Social Capital. Administrative Science Quarterly, 42: 339-65.

Burt, Ronald S. 1987. Social Contagion and Innovation: Cohesion versus structural equivalence. American Journal of Sociology, 92: 1287-335.

Cross, R., S. P. Borgatti, \& A. Parker. 2002. Making invisible workvisible: Using social network analysis to support strategic collaboration. California Management Review, 44(2): 25-+.

De Mesquita, B. B. 1983. The Costs of War - a Rational-Expectations Approach. American Political Science Review, 77(2): 347-57.

De Mesquita, B. B. 1980. An Expected Utility-Theory of International Conflict. American Political Science Review, 74(4): 917-31.

De Mesquita, B. B. 1984. Forecasting Policy Decisions - an Expected Utility Approach to Post-Khomeini Iran. $P S, 17(2)$ : 226-36.

De Mesquita, B. B. 1992. Predicting Politics. Columbus, OH: Ohio State University Press.

De Mesquita, B. B. 1981. Risk, Power Distributions, and the Likelihood of War. International Studies Quarterly, 25(4): 541-68.

De Mesquita, B. B. 1985. The War Trap Revisited - a Revised Expected Utility Model. American Political Science Review, 79(1): 156-77.

De Mesquita, B. B. \& D. Lalman. 1988. Empirical Support for Systemic and Dyadic Explanations of International Conflict. World Politics, 41(1): 1-20.

De Mesquita, B. B. \& D. Lalman. 1987. Modeling War and Peace. American Political Science Review, 81(1): 221-30.

De Mesquita, B. B. \& D. Lalman. 1986. Reason and War. American Political Science Review, 80(4): 111329.

Feder, S. A. 2002. Forecasting for policy making in the post-cold war period. Annual Review of Political Science, 5: 111-25.

Freeman, Linton C., Douglas R. White, \& A. Kimball Romney. 1989. Research methods in social network analysis. Fairfax, Va.: George Mason University Press.

Grossman, Gene M. \& Elhanan Helpman. 2001. Special interest politics. Cambridge, Mass.: MIT. 
Kelly, Alan. 2006. The elements of influence : introducing the Playmaker's Standard: the new essential system for managing competition, reputation, brand, and buzz. New York: Dutton.

Knoke, David. 1996. Comparing policy networks : labor politics in U.S., Germany, and Japan. New York: Cambridge University Press.

Knoke, David. 1990. Organizing for collective action : the political economies of associations. New York: A. de Gruyter.

Knoke, David. 1990. Political networks : the structural perspective. New York: Cambridge University Press.

Knoke, David \& Song Yang. 2008. Social network analysis. 2nd ed. Los Angeles,: Sage Publications.

Laumann, Edward O. \& David Knoke. 1987. The organizational state : social change in national policy domains. Madison, Wis.: University of Wisconsin Press.

Mercken, L., T. Snijders, M. Candel, C. Steglich, \& H. De Vries. 2005. Why adolescents start to smoke: Peer influence versus peer selection processes. Psychology \& Health, 20: 170-70.

Owen-Smith, J. \& W. W. Powell. 2004. Knowledge networks as channels and conduits: The effects of spillovers in the Boston biotechnology community. Organization Science, 15(1): 5-21.

Persson, Torsten \& Guido Enrico Tabellini. 2002. Political economics : explaining economic policy. Cambridge, Mass. London: MIT.

Powell, W. W., D. R. White, K. W. Koput, \& J. Owen-Smith. 2005. Network dynamics and field evolution: The growth of interorganizational collaboration in the life sciences. American Journal of Sociology, 110(4): 1132-205.

Scott, John. 1988. Social Network Analysis. Sociology, 22(1): 109-27.

Snijders, T.A. B., C. E. G. Steglich, \& G.G. van de Bunt. 2008. Introduction to Actor-Based Models for Network Dynamics. Mimeo.

Steglich, C. E. G., T.A. B. Snijders, \& Michael Pearson. 2007. Dynamic Networks and Behavior: Separating Selection from Influence. Mimeo.

Wasserman, Stanley \& Katherine Faust. 1997. Social network analysis : methods and applications. Repr. with corrections. ed. Cambridge [England] ; New York: Cambridge University Press. 